Discussion Papers in Economics

Terms of Trade Shocks and Monetary Policy in India.

Chetan Ghate, Sargam Gupta and Debdulal Mallick

May 2016

Discussion Paper 16-04

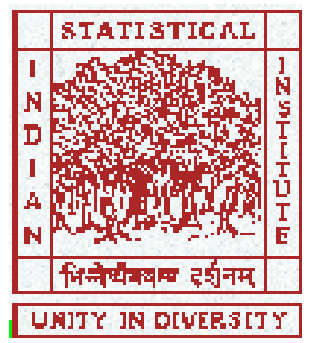

Indian Statistical Institute, Delhi

Economics and Planning Unit

7, S. J. S. Sansanwal Marg, New Delhi 110016, India 


\title{
Terms of Trade Shocks and Monetary Policy in India*
}

\author{
Chetan Ghate ${ }^{\dagger}$ \\ ISI Delhi
}

\author{
Sargam Gupta \\ ISI Delhi
}

May 9, 2016

\author{
Debdulal Mallick § \\ Deakin University
}

\begin{abstract}
Central banks in emerging markets often grapple with understanding the monetary policy response to an inter-sectoral terms of trade shock. To address this, we develop a three sector closed economy NK-DSGE model calibrated to India. Our framework can be generalized to other emerging markets and developing countries. The model is characterized by a manufacturing sector and an agricultural sector. The agricultural sector is disaggregated into a food grain and vegetable sector. The government procures grain from the grain market and stores it. We show that the procurement of grain leads to higher inflation, a change in the sectoral terms of trade, and a positive output gap because of a change in the sectoral allocation of labor. We compare the transmission of a single period positive procurement shock with a single period negative productivity shock and discuss what implications such shocks have for monetary policy setting. Our paper contributes to a growing literature on monetary policy in India and other emerging market economies.
\end{abstract}

Keywords : Multi-sector New Keynesian DSGE Models, Terms of Trade Shocks, Reserve Bank of India, Indian Economy, Agricultural Procurement

JEL Codes: E31; E52; E58; Q18

${ }^{*}$ We thank Partha Sen, Bharat Ramaswami, Serguei Maliar, Jinill Kim, seminar participants at the 2015 Computing in Economics and Finance (CEF) Conference, Taipei, the $4^{\text {th }}$ Delhi Macroeconomics Workshop (ISI Delhi), the 2015 Winter School at the Delhi School of Economics, and the Indian Statistical Institute Delhi for helpful comments. We are grateful to the International Growth Centre for financial support related to this project. We also thank two anonymous referees for useful comments.

${ }^{\dagger}$ Economics and Planning Unit, Indian Statistical Institute, New Delhi-110016, India. Tel: 91-11-41493938. E-mail: cghate@isid.ac.in.

${ }^{\ddagger}$ Corresponding Author: Economics and Planning Unit, Indian Statistical Institute, New Delhi - 110016, India. Tel: 91-11-4149-3942. E-mail: sargam.613r@isid.ac.in.

${ }^{\S}$ Department of Economics, Deakin University, Melbourne, Australia. Tel: +61 3 92517808. Email: debdulal.mallick@deakin.edu.au 


\section{Introduction}

Understanding monetary policy design in emerging markets and developing economies (EMDEs) is a growing area of research. One aspect that is missing in this literature is how distortions in the agriculture sector translate into output and inflation dynamics, and the implications this has for monetary policy setting. In particular, central banks in EMDEs often grapple with understanding the inflationary impact of a shock emanating from the agriculture sector because the precise relationship between aggregate inflation and the terms of trade may be unknown. To address these questions, we develop a three-sector (grain, vegetable, and manufacturing) closed economy NK-DSGE model for the Indian economy to understand how one major distortion - the procurement of grain by the government - affects overall inflationary pressures in the economy via changes in the inter-sectoral terms of trade. Our main contribution is to identify the mechanism through which changes in the terms of trade - because of changes in procurement - leads to aggregate inflation, changes in sectoral output gaps, sectoral resource allocation, and the economy wide output gap. We then calibrate the model to India to discuss the role of monetary policy in such a setup.

Many developing countries, like India, have large agriculture sectors which are inherently volatile. In India, the combined agriculture sector (agriculture, forestry and fishing) comprises 17 per cent of GDP (at constant 2013-14 prices). ${ }^{1}$ The employment share of the agriculture sector in India is also large: 47 per cent in 2013-14. ${ }^{2}$ The Indian government periodically intervenes in the agricultural sector, especially in the food grain market, by directly procuring grain from farmers to create a buffer grain stock to smooth price volatility and for redistribution to the poor. ${ }^{3}$ Non-procured grain becomes available in the market for consumption. By acting like a demand shock, higher procurement increases the market price for grain, because procurement creates a shortage for grain in the open market. Procurement therefore alters the terms of trade between grain and other agricultural goods as well as between agriculture and manufacturing.

Changes in the terms of trade have both demand side and supply side effects thereby affecting output and inflation dynamics in the economy. ${ }^{4}$ The question that arises - for a central bank like the Reserve Bank of India - is how monetary policy should respond to

\footnotetext{
${ }^{1}$ This is for base year of 2011-2012.

${ }^{2}$ Source: Handbook of Statistics on the Indian Economy, Reserve Bank of India and 4th Annual Employment-Unemployment Survey Report 2013-14, Labour Bureau, Government of India.

${ }^{3}$ In India, the government through the Food Corporation of India (FCI), procures and stocks foodgrains, a part of which is released for distribution through the Public Distribution System (PDS) network across the country.

${ }^{4}$ It is worth mentioning that the agriculture sector is also distorted in some way in developed countries, but such distortions may have negligible impacts on the aggregate economy because of a very small share of agriculture in GDP and employment.
} 
changes in the inter-sectoral terms of trade that stem from a procurement shock. In this paper, we analyze the transmission mechanism of a procurement shock through changes in the terms of trade, and how this subsequently affects sectoral wages and marginal costs, sectoral inflation rates, generalized inflation, sectoral output gaps, (labor) re-allocation across sectors, and the economy wide output gap.

We address these issues with a model that has both standard and non-standard features. There are four entities in the economy: a representative household, firms, a government, and a central bank. Households consume open market grain, vegetable, and the manufacturing good. They supply labor to all three sectors. Labor is assumed to be perfectly mobile across sectors. The labor market is assumed to be frictionless. There is a manufacturing sector $(M)$ - which is characterized by staggered price setting and monopolistic competition - and an agricultural sector $(A)$. The agricultural sector, which is also monopolistically competitive, is further disaggregated into a grain $(G)$ and a vegetable $(V)$ sector, which are both characterized by flexible prices. The reason for this disaggregation in the agriculture sector is to incorporate additional imperfections in the agricultural market that are specific to the Indian economy.

We assume that the grain sector has a procurement distortion, which creates a wedge into the price-setting equation of the firms in the grain market. Procuring grain is distortionary because this leads to a shortage of grain in the open market leading to overall inflationary pressures. In India, as part of the procurement policy, the government announces minimum support prices $(M S P)$ before every cropping season for a variety of agricultural commodities. Minimum support prices are the prices at which a farmer can sell the agricultural commodity to the government, and this is typically set above the market price. The procured commodities are then stored in Food Corporation of India (FCI) godowns, from where parts of it are distributed to poor households. The rest of the produce remains in godowns unconsumed and serves as a buffer stock to off-set future supply shocks.

To model the institutional environment in which procurement takes place in India, we follow Basu (2011) and Anand et al. (2016). ${ }^{5}$ We assume that consumers purchase grain at the price prevailing in the open market for grain. This price is determined by the supply and the combined demand for grain by consumers and the government for procurement. In Figure 1, this is represented by the total demand for grain schedule, PP. The demand for

\footnotetext{
${ }^{5}$ Basu (2011, p. 37-38) shows how a distorted food grain market leads to high food inflation and large food grain stocks simultaneously. Anand et al (2016) discuss the role of the government's buffer stock demand for cereal in increasing food inflation in the Indian economy. Ramaswamy et al. (2014) also show how increasing the MSP increases open market prices and fuels food price inflation. They estimate the welfare losses generated from a rising MSP. They find that the welfare losses amount to 1.5 billion dollars to the Indian economy (between 1998-2011).
} 
grain by consumers is given by the schedule, OO. A positive procurement shock leads to an increase in the total demand for grain, which shifts the demand schedule outward from $\mathrm{OO}$ to PP. The increase in demand leads to a change in the market equilibrium from point $X$ to $Z$. The open market price rises from $P^{*}$ to $P_{O G}$, where the new market clearing price, $P_{O G}$, is equal to the MSP. At $P_{O G}$, the supply of grain increases from $O E$ to $O A$. However, the open market grain left for the consumer reduces from $O E$ to $O B$, with the rest of the grain, $A B$, procured. A farmer sells the quantity, $A B$, to the government at the $M S P$ (or at $P_{O G}$ in our model as explained above). Thus, a procurement shock acts like a demand shock in the grain sector, which leads to a higher open market grain price and a lower open market grain quantity. However, the government stops purchasing grain once it meets its targeted amount. We later show that a shock to the public procurement of grain because of an increase in the demand for grain is equivalent to a time varying mark-up shock in the grain sector, i.e., higher procurement raises the mark-up charged by grain sector firms. Procurement therefore acts like a tax on grain consumers.

\section{[ INSERT FIGURE 1]}

To close the model, the central bank implements monetary policy via a simple Taylorstyle interest rate rule.

\subsection{Main Results}

The theoretical contribution of our paper is to provide a rigorous understanding of the general equilibrium effects of procurement shocks using a closed economy NK-DSGE model. In particular, we seek to uncover the transmission mechanism of a positive procurement shock and a negative productivity shock on output and inflation dynamics, and compare their implications for monetary policy design for the Reserve bank of India and other emerging market central banks. We consider these two cases because they typify the kind of shocks experienced by the Indian agriculture sector (upward increase in procurement, bad monsoon).

\subsubsection{Procurement Shock}

On impact, a one period procurement shock increases the price of open market grain. This increases the terms of trade i) between grain and vegetable (intra-sectoral terms of trade), and ii) between the agriculture sector and the manufacturing sector (inter-sectoral terms of trade), making other sectoral goods (vegetable and manufacturing) relatively cheaper. Also, a procurement shock immediately raises the demand for labor in the grain sector leading to 
higher nominal wages in the labor market since the grain sector pulls labor away from other sectors. Because labor is mobile across sectors, nominal wages increase and equalize in all the sectors. The vegetable and manufacturing sector firms raise the prices of their goods in response to higher nominal wages. This is how a procurement shock leads to generalized inflation.

As a response to the rise in inflation the central bank raises the nominal interest rate. The real interest rate, which is the nominal interest rate adjusted for one period ahead expected inflation, rises. A rise in the real interest rate induces a fall in aggregate consumption because of the inter-temporal substitution effect. From the aggregate goods market clearing condition, this would imply that the output produced for consumption (non-procured grain, vegetable, and manufactured goods) will fall. However, because the rise in procured output exceeds the reduction in output produced for consumption, aggregate output increases. This leads to a positive output gap. This further adds to the rise in the interest rate from the Taylor rule.

On impact, from the demand side, the reduction in consumption is consistent with a reduction in the sectoral demand for goods because the income effect from a downward reduction in aggregate consumption off-sets the substitution effect - which induces a higher sectoral demand for goods - due to the change in the intra-sectoral and inter-sectoral terms of trade. More specifically, the income effect reduces the demand for each sectoral good because aggregate consumption falls and sectoral demands are proportionate to aggregate consumption. On the other hand the substitution effect induces an increase in the demand for the manufacturing and the vegetable sector goods as both are now relatively cheaper compared to grain. Because of sectoral goods market clearing, the lower sectoral demand for manufacturing, open market grain, and vegetable, leads to less labor employed in these sectors. However, because aggregate output increases, lower employment in the open market grain $(O G)$ sector, the manufacturing $(M)$ sector, and the vegetable $(V)$ sector, is more than off-set by an increase in labor demand for producing procured grain $(P G)$. Therefore total employment rises. Over time, the real interest rate falls back to its long run value, and consumption rises back to its steady state value. Hence, output approaches its steady state and the output gap goes to zero. As the effect of the procurement shock dampens, the real wage falls over time back to its steady state value, and the sectoral consumption shares, sectoral employment shares, and the intra-sectoral and inter-sectoral terms of trade fully adjust to their original pre-procurement shock levels.

In sum, a one period procurement shock leads to aggregate inflation, a positive output gap and labor reallocation away from the manufacturing and the vegetable sectors. 


\subsubsection{Productivity Shock}

We now discuss the case of a productivity shock. On impact, a one period negative productivity shock increases grain prices and decreases grain output. This increases the terms of trade i) between grain and vegetable (intra-sectoral terms of trade), and ii) between the agriculture sector and the manufacturing sector (inter-sectoral terms of trade), making other sectoral goods (vegetable and manufacturing) relatively cheaper. The demand for vegetable and manufacturing sector goods increases. The vegetable and manufacturing sector goods firms respond to this by increasing their output and which increases their demand for labor. A higher demand for labor in these two sectors leads to higher nominal wages across the economy. The vegetable and manufacturing sector firms raise the prices of their goods in response to higher nominal wages. This is how a negative productivity shock leads to generalized inflation.

Moreover, the manufacturing sector is a sticky price sector and thus only a fraction of firms revise their prices and this creates a negative output gap on impact. At the same time the economy wide output gap also falls slightly. Monetary policy responds to this increase in inflation and slightly negative output gap by an increase in the nominal interest rate. The real interest rate rises. A rise in the real interest rate induces a fall in aggregate consumption because of the inter-temporal substitution effect.

On impact, from the demand side, the reduction in consumption is consistent with a increase in the sectoral demand for goods (vegetable and manufacturing) because the substitution effect due to the increase in the intra-sectoral and inter-sectoral terms of trade off-sets the income effect due to a downward reduction in consumption. The income effect would reduce the demand for each sectoral good. On the other hand the substitution effect would induce an increase in the demand for the manufacturing and the vegetable sector goods as both are relatively cheaper. Because of sectoral goods market clearing, the higher sectoral demand for manufacturing and vegetable leads to more employment in these sectors. As the

effect of the productivity shock dampens, the nominal wage falls over time back to its steady state value, and the sectoral consumption shares, sectoral employment shares, and the intrasectoral and inter-sectoral terms of trade fully adjust to their original pre shock levels. In sum, a one period productivity shock leads to aggregate inflation, a slightly negative output gap and labor reallocation towards the manufacturing and the vegetable sectors.

\subsubsection{Comparison between both shocks}

While both the shocks lead to aggregate inflation, a one period procurement shock leads to a positive economy-wide output gap while a one period negative productivity shock leads 
to a slightly negative economy-wide output gap. The transmission of both the shocks from the grain sector to the other sectors also differs. A positive procurement shock is basically a demand shock in the grain sector which raises the wages in the other sectors. In contrast, a negative productivity shock in the grain sector is a negative supply shock which increases the demand for the other two sector goods and also raises the wages in the other sectors. However, while the procurement shock reallocates the labor away from the vegetable and the manufacturing sector, a negative productivity shock reallocates the labor towards the vegetable and the manufacturing sector.

\subsubsection{NKPC and DIS Equations}

We show that the presence of procurement (under an economically intuitive sufficient condition) changes the aggregate NKPC and DIS curves which affects monetary policy design. A positive steady state procurement level makes the aggregate NKPC steeper which means a given output gap is associated with higher inflation compared to the case when there is no procurement. At the same time a positive steady state procurement level affects the economy wide DIS equation and makes the DIS curve steeper. This implies that the response of the real economy to changes in the real interest rate becomes less strong, thus requiring a stronger monetary response to curb inflation, for a given output gap. This happens because procurement creates a wedge between the output produced and the output consumed. The changes in the real rate of interest affects only output consumed which is a constant proportion of total output. Hence, procurement weakens monetary policy transmission since monetary policy only affects consumed output. Moreover, a positive steady state procurement level distorts the steady state level of all variables which makes aggregate inflation higher and the economy-wide output gap higher. Since monetary policy follows a simple Taylor rule in our model, monetary policy is directly affected by the government's procurement policy.

\subsection{Literature Review}

Our model is most closely related to the seminal work by Gali \& Monacelli (2005) and Aoki (2001). The main difference between our model and these papers is that Gali and Monacelli have an open economy setup while our model assumes a closed economy. In terms of Aoki (2001), while he does not model procurement, in his two sector model, the flexible price sector (the food sector) is distortion free, while in our model the flexible price sectors are not distortion-free. However, similar to Aoki (2001) we explain the transmission of inflation from 
a shock in the flexible sector to the other sectors because of a change in the terms of trade. ${ }^{6}$ Our paper also discusses reasons behind the labor allocation induced in the economy due to these shocks which is not a focus in Aoki (2001). In our framework, grain sector shocks not only shift the aggregate - NKPC (as in Aoki (2001)), but they also changes the slope of the NKPC. In particular, we show that procurement leads to a steepening of the NKPC and DIS curve under a sufficient condition. The procurement distortion therefore affects the responsiveness of the economy to changes in the interest rate which affects the monetary policy response.

A multi-sector model with different sectors has the advantage of allowing one to understand the transmission of sectoral shocks across the economy. A multi-sector setting affects the design of monetary policy depending on the presence of sectoral nominal rigidities and frictions (see Aoki (2001), Benigno (2004), Huang and Liu (2005) and Erceg and Levin (2006)). Importantly, shocks in a multi-sector setting affect relative prices or the terms of trade which have real affects on the economy. Our paper is different from the above papers as much of the literature on terms of trade shocks in multi-sector settings assumes a small open economy setup (see Hove et al. (2012), Rebei and Ortega (2006), Dib et al. (2010)). Although terms of trade shocks in an open economy set-up are important, inter-sectoral terms of trade shocks are also a key concern of monetary policy setting in emerging and developing economies.

\section{The Model}

There are four entities in the economy: a representative household, firms, the government, and a central bank. Households consume open market grain, vegetable, and the manufacturing good. They supply labor to all three sectors. Labor is assumed to be perfectly mobile across sectors. The labor market is assumed to be frictionless. There is a manufacturing sector $(M)$ - which is characterized by staggered price setting and monopolistic competition - and an agricultural sector $(A)$. The agricultural sector, which is also monopolistically competitive, is further disaggregated into a grain $(G)$ and a vegetable $(V)$ sector, which are both characterized by flexible prices. The government sector procures grain. The central bank sets the short term interest rate using a Taylor (1993) style rule. We discuss each sector in detail. ${ }^{7}$

\footnotetext{
${ }^{6}$ Aoki (2001) explains the transmission of inflationary pressures in an economy from a flexible price sector to sticky price sector which leads to generalized inflation.

${ }^{7}$ Derivations for the entire model are in the technical appendix.
} 


\subsection{Households}

An infinitely lived household gets utility from a consumption stream, $C_{t}$, and disutility from labor supply, $N_{t}$. At time 0 , the household maximizes its expected lifetime utility,

$$
E_{0} \sum_{t=0}^{\infty} \beta^{t}\left[U\left(\Gamma_{t} C_{t}\right)-V\left(N_{t}\right)\right]
$$

where $\beta \in(0,1)$ is the discount factor, and $\Gamma_{t}$ is the preference (demand) shock which is assumed to be the same across households and follows an AR(1) process. The utility function is standard and specified as:

$$
\begin{aligned}
U\left(\Gamma_{t} C_{t}\right) & \equiv \frac{\left(\Gamma_{t} C_{t}\right)^{1-\sigma}}{1-\sigma} \\
V\left(N_{t}\right) & \equiv \frac{\left(N_{t}\right)^{1+\psi}}{1+\psi}
\end{aligned}
$$

where, $\sigma$, is the inverse of the inter-temporal elasticity of substitution and, $\psi$, is the inverse of the Frisch elasticity of labor supply. Aggregate consumption, $C_{t}$, is a composite CobbDouglas index of consumption of manufacturing, $C_{M, t}$, and agriculture sector goods, $C_{A, t}$, and is defined as:

$$
C_{t} \equiv \frac{\left(C_{A, t}\right)^{\delta}\left(C_{M, t}\right)^{1-\delta}}{\delta^{\delta}(1-\delta)^{(1-\delta)}}, \quad 0<\delta<1,
$$

where $\delta$ is the share of total consumption expenditure allocated to agriculture sector goods. Agricultural goods, $C_{A, t}$, is again a composite Cobb-Douglas index of consumption of grain bought by the consumers in the open market, $C_{O G, t}$, and vegetable, $C_{V, t}$, and is defined as:

$$
C_{A, t} \equiv \frac{\left(C_{V, t}\right)^{\mu}\left(C_{O G, t}\right)^{1-\mu}}{\mu^{\mu}(1-\mu)^{(1-\mu)}}, \quad 0<\mu<1
$$

with $\mu$ being the share of total food expenditure allocated to vegetable sector goods. Consumption in each of the three sectors, $C_{M, t}, C_{O G, t}$ and $C_{V, t}$ is a CES aggregate of a continuum of differentiated goods in the respective sector indexed by $j \in[0,1]: C_{M, t} \equiv$ $\left(\int_{0}^{1} C_{M, t}(j)^{\frac{\theta-1}{\theta}} d j\right)^{\frac{\theta}{\theta-1}} ; C_{O G, t} \equiv\left(\int_{0}^{1} C_{O G, t}(j)^{\frac{\theta-1}{\theta}} d j\right)^{\frac{\theta}{\theta-1}}$ and $C_{V, t} \equiv\left(\int_{0}^{1} C_{V, t}(j)^{\frac{\theta-1}{\theta}} d j\right)^{\frac{\theta}{\theta-1}}$, where $\theta>1$ is the elasticity of substitution between the varieties within each sector and is assumed to be the same in all sectors.

Each household maximizes its lifetime utility given by equation (1) subject to an inter- 
temporal budget constraint

$$
\begin{gathered}
\int_{0}^{1} P_{O G, t}(j) C_{O G, t}(j) d j+\int_{0}^{1} P_{V, t}(j) C_{V, t}(j) d j+\int_{0}^{1} P_{M, t}(j) C_{M, t}(j) d j \\
+E_{t}\left\{Q_{t, t+1} B_{t+1}\right\} \leqslant B_{t}+W_{t} N_{t}-T_{t}+D i v_{t}
\end{gathered}
$$

where $P_{s, t}(j)$ is the price of variety $j$ in sector $s=O G, V$, and $M . B_{t+1}$ is the nominal pay-off in period $t+1$ of the bond held at the end of period $t . Q_{t, t+1}$ is the stochastic discount factor. The transversality condition, $\lim _{T \rightarrow \infty} E_{t}\left\{B_{t}\right\} \geq 0 \forall t$, is assumed to be satisfied. $W_{t}$ is the economy wide nominal wage rate. $T_{t}$ are lump-sum taxes to the government, and Div $v_{t}$ are the dividends or profits distributed to the households by monopolistically competitive firms. Money is excluded from both the budget constraint and utility function as the demand for money is endogenized.

Optimal consumption expenditure allocations are given as solutions to maximizing the composite consumption index subject to a given level of expenditure level. For the agricultural and manufacturing goods, the optimal allocations are: ${ }^{8}$

$$
\begin{aligned}
C_{A, t} & =\delta\left(\frac{P_{A, t}}{P_{t}}\right)^{-1} C_{t} \\
C_{M, t} & =(1-\delta)\left(\frac{P_{M, t}}{P_{t}}\right)^{-1} C_{t}
\end{aligned}
$$

where the aggregate price index for the economy, or equivalently the consumer price index (CPI), is $P_{t} \equiv\left(P_{A, t}\right)^{\delta}\left(P_{M, t}\right)^{1-\delta}$ with $P_{A, t}$ and $P_{M, t}$ being the prices of the composite agricultural and manufacturing goods, respectively. Similarly, the optimal allocations of grain and vegetable are given by, respectively,

$$
\begin{aligned}
C_{O G, t} & =(1-\mu)\left(\frac{P_{O G, t}}{P_{A, t}}\right)^{-1} C_{A, t} \\
C_{V, t} & =\mu\left(\frac{P_{V, t}}{P_{A, t}}\right)^{-1} C_{A, t},
\end{aligned}
$$

where the price of agricultural goods is given by, $P_{A, t} \equiv\left(P_{V, t}\right)^{\mu}\left(P_{O G, t}\right)^{1-\mu}$. Finally, the optimal allocation within each category of goods gives the following demand functions for the $j^{\text {th }}$ variety in the $s^{\text {th }}$ sector:

$$
C_{s, t}(j)=\left(\frac{P_{s, t}(j)}{P_{s, t}}\right)^{-\theta} C_{s, t} \text { for all } j \in[0,1]
$$

\footnotetext{
${ }^{8}$ For details, refer to the technical appendix.
} 
for $s=O G, V$, and $M$, and $P_{s, t} \equiv\left(\int_{0}^{1} P_{s, t}(j)^{1-\theta} d j\right)^{\frac{1}{1-\theta}}$ is the sector $s$ specific price index.

Combining equations $(7)-(11)$, it is straightforward to show that $\int_{0}^{1} P_{O G, t}(j) C_{O G, t}(j) d j+$ $\int_{0}^{1} P_{V, t}(j) C_{V, t}(j) d j+\int_{0}^{1} P_{M, t}(j) C_{M, t}(j) d j=P_{t} C_{t}$. Therefore, the budget constraint (6) can be rewritten as

$$
P_{t} C_{t}+E_{t}\left\{Q_{t, t+1} B_{t+1}\right\} \leqslant B_{t}+W_{t} N_{t}-T_{t}+\operatorname{Div}_{t}
$$

The solution to maximizing (1) subject to (12) yields the following optimality conditions:

$$
\begin{gathered}
E_{t}\left[\beta R_{t}\left(\frac{\Gamma_{t+1}}{\Gamma_{t}}\right)^{1-\sigma}\left(\frac{C_{t+1}}{C_{t}}\right)^{-\sigma} \frac{P_{t}}{P_{t+1}}\right]=1 \\
\frac{\left(N_{t}\right)^{\psi}}{\left(\Gamma_{t}\right)^{1-\sigma}\left(C_{t}\right)^{-\sigma}}=\frac{W_{t}}{P_{t}}
\end{gathered}
$$

where $R_{t}=\frac{1}{E_{t}\left\{Q_{t, t+1}\right\}}$ is the gross nominal return on the riskless one-period bond. Equation (13) is the Euler equation. Equation (14) is the optimal labor supply equation.

\subsection{Terms of Trade: Some Useful Identities}

Before proceeding further, we introduce several definitions and identities that will be used in the rest of the paper. CPI inflation is the change in the aggregate price index and is given by $\pi_{t}=\ln P_{t}-\ln P_{t-1}$. Using the definition of the aggregate price index, CPI inflation can be expressed as a weighted average of sectoral inflation rates: $\pi_{t}=\delta \pi_{A, t}+(1-\delta) \pi_{M, t}$, where $\pi_{A, t}$ and $\pi_{M, t}$ are inflation in the agricultural and manufacturing goods prices, respectively. Similarly, the inflation in agricultural goods prices can be further disaggregated as the weighted average of inflation in the grain and vegetable prices ( $\pi_{O G, t}$ and $\pi_{V, t}$, respectively): $\pi_{A, t}=(1-\mu) \pi_{O G, t}+\mu \pi_{V, t}$. Therefore, CPI inflation can be expressed in terms of sectoral inflation rates as:

$$
\pi_{t}=\delta(1-\mu) \pi_{O G, t}+\delta \mu \pi_{V, t}+(1-\delta) \pi_{M, t} .
$$

Defining the terms of trade (TOT) between agriculture and manufacturing (inter-sectoral), and also that between grain and vegetable within the agricultural sector (intra-sectoral) is important because of their role in influencing aggregate output and inflation dynamics. We define the inter-sectoral TOT as

$$
T_{A M, t} \equiv \frac{P_{A, t}}{P_{M, t}},
$$

and the intra-sectoral TOT as

$$
T_{O G V, t} \equiv \frac{P_{O G, t}}{P_{V, t}} .
$$


Equations (16) and (17) reveal that changes in the TOT can be expressed in terms of sectoral inflation rates: ${ }^{9}$

$$
\Delta \widehat{T}_{A M, t}=\pi_{A, t}-\pi_{M, t}
$$

and

$$
\Delta \widehat{T}_{O G V, t}=\pi_{O G, t}-\pi_{V, t} .
$$

Combining equations (15) with (18) and (19), CPI inflation dynamics can be shown to be directly related to the inter-sectoral TOT and intra-sectoral TOT. This is given by

$$
\pi_{t}=\pi_{O G, t}-\mu \Delta \widehat{T}_{O G V, t}-(1-\delta) \Delta \widehat{T}_{A M, t} .
$$

The interpretation of equation (20) is the same as equation (15). Deteriorations of both the intra-sectoral TOT (i.e., relatively higher inflation in vegetable), and inter-sectoral TOT (i.e., relatively higher inflation in manufacturing relative to agriculture) increase CPI inflation. It will be shown later that these changes in the terms of trade alter resource allocation across sectors thus playing a critical role for the sectoral allocation of resources in the economy.

\section{$2.3 \quad$ Firms}

In our model, firms in the three sectors differ only in their price setting behavior. Otherwise, they are similar in terms of their production technology and the market structure. All three markets are monopolistically competitive. Prices in both the grain and vegetable sectors are fully flexible, while in the manufacturing sector prices are set in a staggered fashion outlined below. Crucially, as mentioned in the introduction, the grain sector differs from the vegetable sector due to the government procurement of grain. Our model departs crucially from Aoki (2001) in this respect model as the agriculture sector in Aoki (2001) is characterized both by flexible prices and perfect competition.

We assume that in each sector, $s$, there are a continuum of firms indexed by $j \in[0,1]$. Each firm produces a differentiated good using, $N_{s, t}(j)$, units of labor:

$$
Y_{s, t}(j)=A_{s, t} N_{s, t}(j)
$$

for $s=G, V$ and $M$. Here, $A_{s, t}$, is the sector-specific level of technology and its (log)

\footnotetext{
${ }^{9}$ Variable $\widehat{X}_{t}$, is the log-deviation from steady state and is defined as,
}

$$
\widehat{X}_{t}=\ln X_{t}-\ln X
$$


first-difference follows an $\mathrm{AR}(1)$ process, i.e., $\Delta \ln A_{s, t}=\rho_{s} \Delta \ln A_{s, t-1}+\epsilon_{s, t}$. The nominal marginal cost of production in sector $s$ is given by,

$$
M C_{s, t}=\frac{W_{t}}{M P L_{s, t}}=\frac{W_{t}}{A_{s, t}}
$$

where $M P L_{s, t}$ is the marginal product of labor in sector $s$, where $s=G, . V$ and $M$. Using the definitions of the terms of trades, the sectoral real marginal cost $\left(m c_{s, t}=\frac{M C_{s, t}}{P_{s, t}}\right)$ for the grain, vegetable and manufacturing sectors, respectively, can be rewritten as

$$
\begin{aligned}
m c_{G, t} & =\frac{1}{A_{G, t}} \frac{W_{t}}{P_{t}}\left(T_{A M, t}\right)^{-(1-\delta)}\left(T_{O G V, t}\right)^{-\mu} \\
m c_{V, t} & =\frac{1}{A_{V, t}} \frac{W_{t}}{P_{t}}\left(T_{A M, t}\right)^{-(1-\delta)}\left(T_{O G V, t}\right)^{(1-\mu)}, \text { and } \\
m c_{M, t} & =\frac{1}{A_{M, t}} \frac{W_{t}}{P_{t}}\left(T_{A M, t}\right)^{\delta} .
\end{aligned}
$$

Let

$$
Y_{s, t} \equiv\left(\int_{0}^{1} Y_{s, t}(j)^{\frac{\theta-1}{\theta}} d j\right)^{\frac{\theta}{\theta-1}}
$$

represent an index for aggregate sectoral output consumed for $s=O G, V$, and $M$, analogous to the one introduced for consumption. ${ }^{10}$ Output demand will be given by

$$
Y_{s, t}(j)=\left(\frac{P_{s, t}(j)}{P_{s, t}}\right)^{-\theta} Y_{s, t} .
$$

The sectoral labor supply allocation is then obtained as:

$$
\begin{aligned}
N_{s, t} & \equiv \int_{0}^{1} N_{s, t}(j) d j=\frac{1}{A_{s, t}} \int_{0}^{1} Y_{s, t}(j) d j=\frac{Y_{s, t}}{A_{s, t}} \int_{0}^{1}\left(\frac{P_{M, t}(j)}{P_{M, t}}\right)^{-\theta} d j=\frac{Y_{s, t} Z_{s, t}}{A_{s, t}} \\
\text { for } s & =O G, V, \text { and } M .
\end{aligned}
$$

The last line in the above equation uses the sectoral output demand equation. ${ }^{11}$ Here $Z_{s, t}=$ $\int_{0}^{1}\left(\frac{P s, t(j)}{P s, t}\right)^{-\theta} d j$ represents the price dispersion term. The price dispersion term would be

\footnotetext{
${ }^{10}$ Note that for the grain sector $(G)$ only open market output, $Y_{O G, t}$, is consumed while the rest, $Y_{P G, t}$, is procured by the government. The total sectoral output produced in the grain sector is defined as, $Y_{G, t}=$ $Y_{O G, t}+Y_{P G, t}$.

${ }^{11}$ For the grain sector,

$N_{G, t} \equiv \int_{0}^{1} N_{G, t}(j) d j=\int_{0}^{1} \frac{Y_{G, t}(j)}{A_{G, t}} d j=\int_{0}^{1} \frac{\left(Y_{P G, t}(j)+Y_{O G, t}(j)\right)}{A_{G, t}} d j=\frac{1}{A_{G, t}}\left\{\int_{0}^{1} Y_{P G, t}(j) d j+\int_{0}^{1} Y_{O G, t}(j) d j\right\}=$ $\frac{1}{A_{G, t}}\left\{Y_{P G, t}+Y_{O G, t} Z_{O G, t}\right\}$.
} 
their only for the sticky price sector i.e., only the manufacturing sector and for the flexible price sectors it would be one. ${ }^{12}$ However, equilibrium variations in $\ln Z_{M, t}$ around the perfect foresight steady state are of higher order, and therefore, this term drops out for up to a first order approximation (See appendix C in Gali and Monacelli, 2005).

\subsubsection{The Grain Sector and Price Setting}

To model the institutional environment for price-setting in the grain sector, we assume that total grain produced is the sum of the amount consumed and procured. Let the government procure, $Y_{P G, t}(j)$, of each variety, $j$, at the market price, $P_{O G, t}(j)$. For simplicity and without loss of generality, assume that the government procures an equal amount of each variety so that $Y_{P G, t}(j)=Y_{P G, t} \forall j$. Therefore, $Y_{G, t}(j)=Y_{P G, t}+Y_{O G, t}(j)$. Our set-up follows Figure 1 described in the introduction, where higher demand for the grain due to procurement, $Y_{P G, t}$, increases the market price from the market clearing level, $P^{*}$, to the higher price level, $P_{O G}$. Note that in our model, the higher price level at time $t, P_{O G, t}$, is the same as the minimum support price at time $t\left(\mathrm{MSP}_{t}\right)$. In other words, the government announces the amount of grain it wants to procure, $Y_{P G, t}$, based on a given $\mathrm{MSP}_{t}$ it wants to set. ${ }^{13}$ The grain sector firms take the announced procurement amount as given and set prices, $P_{O G, t}$, optimally.

We assume that prices are flexible in the grain sector so that each firm, $j$, sets its price, $P_{O G, t}(j)$, to maximize profits, $\pi_{O G, t}(j)$, given by

$$
\pi_{O G, t}(j)=P_{O G, t}(j)\left[Y_{O G, t}(j)+Y_{P G, t}\right]-M C_{G, t}\left[Y_{O G, t}(j)+Y_{P G, t}\right],
$$

subject to the demand constraint

$$
Y_{O G, t}(j)=\left(\frac{P_{O G, t}(j)}{P_{O G, t}}\right)^{-\theta} Y_{O G, t}
$$

in every period, for each variety $j$. The downward sloping demand curve for the $j^{\text {th }}$ variety reflects the fact that farmers have some monopoly power. ${ }^{14}$ Profit maximization results in

\footnotetext{
${ }^{12}$ This implies $Z_{O G, t}=Z_{V, t}=1$ and $Z_{M, t}=\int_{0}^{1}\left(\frac{P_{M, t}(j)}{P_{M}, t}\right)^{-\theta} d j$.

${ }^{13}$ We assume that the government in our model has complete information about the demand and supply schedules in the open market for grain. There is, however, some persistence in the amount of procurement, $Y_{P G, t}$, undertaken by the government every year. In the calibration exercise, we assume that procurement follows an $\operatorname{AR}(1)$ process which we estimate from the Indian data.

${ }^{14}$ We justify this assumption by noting that many large farmers in India are also traders, and hence can be viewed as "farmer-traders."
} 
the following price setting equation,

$$
P_{O G, t}(j)=\frac{\theta}{(\theta-1)-\frac{Y_{P G, t}}{Y_{O G, t}(j)}} M C_{G, t} .
$$

Here $\frac{\theta}{\theta-1}$ is the standard price markup over marginal cost that is due to monopolistic com-

petition. The $\frac{Y_{P G, t}}{Y_{O G, t}(j)}$ term in the denominator is the ratio of the amount procured by the government relative to the amount available in the open market. This term is new and appears due to the additional friction in the grain market resulting from the procurement of grain. In the absence of this term, equation (27) gives the standard equilibrium price under flexible price setting. A positive shock to procurement raises the term, $\frac{Y_{P G, t}}{Y_{O G, t}(j)}$, and leads to an increase in the mark-up. Moreover, the procurement shock also acts as a time-varying mark-up shock in the grain sector.

\subsubsection{The Vegetable Sector and Price Setting}

Prices are also assumed to be flexible in the vegetable sector. Each firm $j$ can revise its price, $P_{V, t}(j)$, in every period to maximize profits,

$$
\pi_{V, t}(j)=P_{V, t}(j) Y_{V, t}(j)-M C_{V, t} Y_{V, t}(j),
$$

subject to the demand constraint

$$
Y_{V, t}(j)=\left(\frac{P_{V, t}(j)}{P_{V, t}}\right)^{-\theta} Y_{V, t},
$$

for variety $j$. Profit maximization results in the following price setting equation,

$$
P_{V, t}(j)=\frac{\theta}{\theta-1} M C_{V, t}
$$

Equation (28) shows that all firms in the vegetable sector set the same price given the same marginal cost and markup. Note that the only distortion in this sector is this price markup, which is due to monopolistic competition.

\subsubsection{The Manufacturing Sector and Price Setting}

The manufacturing sector differs from the two other sectors in terms of its price setting behavior. Prices are sticky in this sector and are set a la Calvo (1983). Firms adjust prices with probabilities $\left(1-\alpha_{M}\right)$ independent of the time passed since the previous adjustment. 
By the law of large numbers a fraction of $\left(1-\alpha_{M}\right)$ firms adjust prices while the rest of the firms do not. Price re-setting firm $j$ sets a new price at period $t$ to maximize the current value of all future profits,

$$
\max _{P_{M, t}^{*}(j)} E_{t} \sum_{k=0}^{\infty} \alpha_{M}^{k} Q_{t, t+k}\left[P_{M, t}^{*}(j)-M C_{M, t+k}\right] Y_{M, t+k}(j)
$$

subject to the demand constraint

$$
Y_{M, t+k}(j)=\left(\frac{P_{M, t}^{*}(j)}{P_{M, t+k}}\right)^{-\theta} Y_{M, t+k}
$$

Profit maximization results in the following price setting equation,

$$
P_{M, t}^{*}(j)=\frac{\theta}{\theta-1} \frac{E_{t} \sum_{k=0}^{\infty} \alpha_{M}^{k} Q_{t, t+k} Y_{M, t+k}(j) M C_{M, t+k}}{E_{t} \sum_{k=0}^{\infty} \alpha_{M}^{k} Q_{t, t+k} Y_{M, t+k}(j)} .
$$

The above equation shows that the manufacturing sector price is a markup over weighted current and expected future marginal costs. It is important to mention that under flexible prices, firms change their price whenever they get a chance to do so; therefore, the above optimal dynamic price setting boils down to its static counterpart similar to equation (28) as:

$$
P_{M, t}^{*}(j)=\frac{\theta}{\theta-1} M C_{M, t}
$$

Under sticky price setting, the dynamics of the manufacturing sector price index is given by:

$$
P_{M, t}^{1-\theta}=\alpha_{M}\left(P_{M, t-1}\right)^{1-\theta}+\left(1-\alpha_{M}\right)\left(P_{M, t}^{*}\right)^{1-\theta}
$$

Note that the nominal marginal cost entering equations (27), (28) and (29) are given by equation (22).

\section{Equilibrium Dynamics}

\subsection{Market Clearing}

Markets clear for each variety $j$ in all three sectors. These can be written as: $C_{M, t}(j)=$ $Y_{M, t}(j), C_{O G, t}(j)+Y_{P G, t}=Y_{G, t}(j)$ and $C_{V, t}(j)=Y_{V, t}(j)$. Aggregating over all $j$, using the 
CES aggregator on consumption of sectoral goods as assumed in Section 2.1, we get

$$
\begin{aligned}
C_{M, t} & =Y_{M, t} \\
C_{V, t} & =Y_{V, t} \\
C_{O G, t} & =Y_{O G, t} \\
Y_{O G, t}+Y_{P G, t} & =Y_{G, t} .
\end{aligned}
$$

The government budget constraint is

$$
G_{t}=T_{t}=\frac{P_{O G, t}}{P_{t}} Y_{P G, t} \quad \forall t
$$

$Y_{t}$, or aggregate output, can be written in "consumption-bundle" terms as,

$$
Y_{t}=C_{t}+\frac{P_{O G, t}}{P_{t}} Y_{P G, t}
$$

The above equation is the aggregate goods market clearing condition and can be re-written as,

$$
Y_{t}=C_{t}+\left(T_{O G V, t}\right)^{\mu}\left(T_{A M, t}\right)^{1-\delta} Y_{P G, t}
$$

Finally, the labor market clearing condition is given by,

$$
N_{t}=N_{G, t}+N_{V, t}+N_{M, t}
$$

\subsection{The Steady State}

Define $X$ (without $t$ subscript) as the steady state value of the variable, $X_{t}$. Assuming no trend growth in productivity, the steady state value of $A_{s}=1$ for $s=G, V$, and $M$. From equation (22), we have

$$
M C_{s}=W
$$

for $s=G, V$, and $M$. Steady state sectoral prices can be expressed as,

$$
\begin{aligned}
P_{M} & =P_{V}=\frac{\theta}{(\theta-1)} W, \\
P_{O G} & =\frac{\theta}{(\theta-1)-\frac{c_{p}}{1-c_{p}}} W,
\end{aligned}
$$


where $c_{p}=\frac{Y_{P G}}{Y_{G}}$ is the steady state share of grain procured by the government. This gives the aggregate price level,

$$
P=(1 / \gamma)^{\delta(1-\mu)} \frac{\theta}{(\theta-1)} W
$$

where $\gamma=\frac{(\theta-1)\left(1-c_{p}\right)-c_{p}}{(\theta-1)\left(1-c_{p}\right)} \cdot{ }^{15}$ Therefore, the above sectoral prices can also be rearranged as,

$$
\begin{aligned}
P_{M} & =P_{V}=\gamma^{\delta(1-\mu)} P \\
P_{O G} & =(1 / \gamma)^{1-\delta(1-\mu)} P
\end{aligned}
$$

The steady state intra-sectoral and inter-sectoral TOT are,

$$
\begin{aligned}
T_{O G V} & =1 / \gamma \\
T_{A M} & =(1 / \gamma)^{1-\mu}
\end{aligned}
$$

respectively. Sectoral steady state consumption demands are:

$$
\begin{aligned}
C_{M} & =(1-\delta) \gamma^{-\delta(1-\mu)} C \\
C_{V} & =\mu \delta \gamma^{-\delta(1-\mu)} C \\
C_{O G} & =(1-\mu) \delta \gamma^{-\delta(1-\mu)+1} C .
\end{aligned}
$$

Steady state aggregate employment is derived from sectoral employment and market clearing conditions:

$$
N=N_{G}+N_{V}+N_{M}=\gamma^{-\delta(1-\mu)}[1+(\gamma-1)(1-\mu) \delta] C+Y_{P G}
$$

\subsection{The Log-Linearized Model}

Given the steady state, we log-linearize the key relationships. Log-linearization of the Euler equation (13) and the labor supply equation (14) yields the following two equations:

$$
\begin{aligned}
\widehat{C}_{t} & =E_{t}\left\{\widehat{C}_{t+1}\right\}-\frac{1}{\sigma}\left[\left(\widehat{R}_{t}-E_{t}\left\{\pi_{t+1}\right\}\right)+(1-\sigma) E_{t}\left\{\Delta \widehat{\Gamma}_{t+1}\right\}\right] \\
\widehat{W}_{t}-\widehat{P}_{t} & =\psi \widehat{N}_{t}+\sigma \widehat{C}_{t}-(1-\sigma) \widehat{\Gamma}_{t}
\end{aligned}
$$

where $\widehat{R}_{t}-E_{t}\left\{\pi_{t+1}\right\}$ is the (ex-ante) real interest rate. The sectoral real marginal costs (see equations $(23 \mathrm{a})-(23 \mathrm{c})$ ), expressed in terms of the aggregate real wage, sectoral productivity

\footnotetext{
${ }^{15}$ Since prices cannot be negative $\gamma$ should be greater then zero such that $0 \leq \gamma \leq 1$. Imposing this restriction implies $0 \leq c_{p} \leq \frac{\theta-1}{\theta}$.
} 
shocks, and terms of trade terms, are log-linearized to obtain the following expressions:

$$
\begin{aligned}
\widehat{m c}_{G, t} & =\widehat{W}_{t}-\widehat{P}_{t}-\widehat{A}_{G, t}-(1-\delta) \widehat{T}_{A M, t}-\mu \widehat{T}_{O G V, t} \\
\widehat{m c}_{V, t} & =\widehat{W}_{t}-\widehat{P}_{t}-\widehat{A}_{V, t}-(1-\delta) \widehat{T}_{A M, t}+(1-\mu) \widehat{T}_{O G V, t} \\
\widehat{m c}_{M, t} & =\widehat{W}_{t}-\widehat{P}_{t}-\widehat{A}_{M, t}+\delta \widehat{T}_{A M, t}
\end{aligned}
$$

The sectoral employment equation (26) for the vegetable and manufacturing sectors are log-linearized as

$$
\widehat{N}_{s, t}=\widehat{Y}_{s, t}-\widehat{A}_{s, t}
$$

for $s=V$ and $M$. For the grain sector, it is log-linearized as

$$
\widehat{N}_{G, t}=c_{p} \widehat{Y}_{P G, t}+\left(1-c_{p}\right) \widehat{Y}_{O G, t}-\widehat{A}_{s, t}
$$

where $c_{p}$ is the steady state share of grain procured $\left(Y_{P G} / Y_{G}\right)$.

Combining the log-linearized sectoral demand equations $((7)$ - (10)) and sectoral market clearing conditions, ((32a) - (32c)), sectoral output levels can be expressed in terms of aggregate consumption and terms of trade as:

$$
\begin{aligned}
\widehat{Y}_{M, t} & =\widehat{C}_{t}+\delta \widehat{T}_{A M, t} \\
\widehat{Y}_{O G, t} & =\widehat{C}_{t}-\mu \widehat{T}_{O G V, t}-(1-\delta) \widehat{T}_{A M, t} \\
\widehat{Y}_{V, t} & =\widehat{C}_{t}+(1-\mu) \widehat{T}_{O G V, t}-(1-\delta) \widehat{T}_{A M, t}
\end{aligned}
$$

The aggregate goods market clearing equilibrium, equation (35), is log linearized as:

$$
\widehat{Y}_{t}=\left(1-\lambda_{c}\right) \widehat{C}_{t}+\lambda_{c}\left[\widehat{Y}_{P G, t}+\mu \widehat{T}_{O G V, t}+(1-\delta) \widehat{T}_{A M, t}\right]
$$

where $\lambda_{c}=\gamma^{\delta(1-\mu)-1} c_{p} s_{g}$ and we define $s_{g}=\frac{Y_{G}}{Y}=\frac{\delta(1-\mu)}{1-c_{p}(1-\delta(1-\mu))}$ as the steady state share of grain sector output to total output. As can be seen in equation (44), the procurement of grain creates a wedge between aggregate output and aggregate consumption. Log-linearizing the labor market clearing condition (36), and then substituting sectoral employment in terms of sector-specific output and productivity levels gives us:

$$
\widehat{N}_{t}=\Theta_{1}\left[\widehat{C}_{t}-\widehat{A}_{t}+(1-\mu)(\gamma-1) \delta\left(\widehat{Y}_{O G, t}-\widehat{A}_{G, t}\right)\right]+\Theta_{2}\left(\widehat{Y}_{P G, t}-\widehat{A}_{G, t}\right)
$$




$$
\begin{aligned}
& \text { where } \widehat{C}_{t}=(1-\mu) \delta \widehat{C}_{O G, t}+\mu \delta \widehat{C}_{V, t}+(1-\delta) \widehat{C}_{M, t} \\
& \widehat{A}_{t}=(1-\mu) \delta \widehat{A}_{G, t}+\mu \delta \widehat{A}_{V, t}+(1-\delta) \widehat{A}_{M, t} \\
& \Theta_{1}=\frac{\left(1-c_{p} s_{g} \gamma^{[\delta(1-\mu)-1]}\right) \gamma^{-\delta(1-\mu)}}{\gamma^{-\delta(1-\mu)}[1+(1-\mu)(\gamma-1) \delta]\left(1-c_{p} s_{g} \gamma^{[\delta(1-\mu)-1]}\right)+c_{p} s_{g}} \\
& \Theta_{2}=\frac{c_{p} s_{g}}{\gamma^{-\delta(1-\mu)}[1+(1-\mu)(\gamma-1) \delta]\left(1-c_{p} s_{g} \gamma^{[\delta(1-\mu)-1]}\right)+c_{p} s_{g}}
\end{aligned}
$$

Log-linearizing and combining equations (29) and (31) yields the NKPC (New Keynesian Phillips Curve) in the manufacturing sector (for details, see Gali (2008, Chapter 3)

$$
\begin{aligned}
\pi_{M, t} & =\beta E_{t}\left\{\pi_{M, t+1}\right\}+\lambda_{M} \widehat{m c}_{M, t} \\
\text { where } \lambda_{M} & =\frac{\left(1-\alpha_{M}\right)\left(1-\alpha_{M} \beta\right)}{\alpha_{M}} .
\end{aligned}
$$

Note that the above log-linearized expression of the price setting equation in the manufacturing sector is independent of $\theta$, the elasticity of substitution between the varieties within this sector. Similarly, the log linearized expression of the pricing equation (48) in the vegetable sector as shown below is independent of $\theta$. However, a similar log-linearized price setting equation (49) to the grain sector is not independent of $\theta$ as shown below

$$
\begin{gathered}
\widehat{m c}_{V, t}=0, \\
\widehat{m c}_{G, t}=\left(\frac{c_{p}}{(\theta-1)\left(1-c_{p}\right)-c_{p}}\right)\left(\widehat{Y}_{O G, t}-\widehat{Y}_{P G, t}\right) .
\end{gathered}
$$

It should be noted that assuming different values of $\theta$ for different sectors will not change the dynamics as only $\theta$ for the grain sector, $\theta_{G}$, will shows up in the log-linearized (up to first order) system of equations of the model. This would be equivalent to assuming the same value of $\theta$ for different sectors.

\subsubsection{Shock processes}

The structural shock processes in log-linearized form are assumed to follow AR(1) processes, ${ }^{16}$

$$
\begin{aligned}
\Delta \ln A_{G, t} & =\rho_{A_{G}} \Delta \ln A_{G, t-1}+\epsilon_{A_{G}, t}, \epsilon_{A_{G}, t} \sim i . i . d .\left(0, \sigma_{A_{G}}\right) \\
\Delta \ln A_{V, t} & =\rho_{A_{V}} \Delta \ln A_{V, t-1}+\epsilon_{A_{V}, t}, \epsilon_{A_{V}, t} \sim i . i . d . \quad\left(0, \sigma_{A_{V}}\right) \\
\Delta \ln A_{M, t} & =\rho_{A_{M}} \Delta \ln A_{M, t-1}+\epsilon_{A_{M}, t}, \epsilon_{A_{M}, t} \sim i . i . d . \quad\left(0, \sigma_{A_{M}}\right) \\
\ln Y_{P G, t}-\ln Y_{P G} & =\rho_{Y_{P G}}\left(\ln Y_{P G, t-1}-\ln Y_{P G}\right)+\epsilon_{Y_{P G}, t}, \epsilon_{Y_{P G}, t} \sim i . i . d . \quad\left(0, \sigma_{Y_{P G}}(50 \mathrm{~d})\right.
\end{aligned}
$$

\footnotetext{
${ }^{16}$ We ignore demand shocks in the paper.
} 


\subsubsection{The flexible-price equilibrium and the natural level}

Under flexible prices, the pricing decisions of firms are synchronized. We have sticky prices only in the manufacturing sector. Under flexible prices, price setting boils down to a static decision and each firm sets price by equation (30): $P_{M, t}^{*}=\frac{\theta}{\theta-1} M C_{M, t}$, which implies a constant real marginal cost. This in turn implies that the real marginal cost log-deviation is zero. We already have flexible prices in both the agricultural sub-sectors. However, given procurement in the grain sector, the real marginal cost log-deviation is non-zero. This is given by the log-linearization of equation (27),

$$
\widehat{m c}_{G, t}^{n}=\Phi\left(\widehat{Y}_{O G, t}^{n}-\widehat{Y}_{P G, t}\right) .
$$

where $\Phi=\frac{c_{p}}{(\theta-1)\left(1-c_{p}\right)-c_{p}}$. The superscript, $n$, is used to denote the natural level of a variable. Here, it is important to stress that the grain procured by the government will be the same under any pricing assumption, so that $\widehat{Y}_{P G, t}=\widehat{Y}_{P G, t}^{n}$. In the case of manufacturing and vegetable sectors, $\widehat{m c}_{V, t}^{n}=\widehat{m c}_{M, t}^{n}=0$. Using these conditions for the real marginal cost log-deviation, equations $(41 a-41 c)$ can be expressed as

$$
\begin{aligned}
\widehat{T}_{O G V, t}^{n} & =-\Phi\left(\widehat{Y}_{O G, t}^{n}-\widehat{Y}_{P G, t}\right)+\widehat{A}_{V, t}-\widehat{A}_{G, t} \\
\widehat{T}_{A M, t}^{n} & =-\Phi(1-\mu)\left(\widehat{Y}_{O G, t}^{n}-\widehat{Y}_{P G, t}\right)+\widehat{A}_{M, t}-(1-\mu) \widehat{A}_{G, t}-\mu \widehat{A}_{V, t}
\end{aligned}
$$

The Euler equation can be rewritten in the flexible price equilibrium as,

$$
\widehat{C}_{t}^{n}=E_{t}\left\{\widehat{C}_{t+1}^{n}\right\}-\frac{1}{\sigma}\left[\left(\widehat{R}_{t}^{n}-E_{t}\left\{\pi_{t+1}^{n}\right\}\right)+(1-\sigma) E_{t}\left\{\Delta \widehat{\Gamma}_{t+1}\right\}\right],
$$

where $\widehat{R}_{t}^{n}$ and $\pi_{t}^{n}$ denote the nominal interest rate and inflation rate under flexible price setting. At a flexible price equilibrium the real wage equation can be derived as

$$
\widehat{w}_{t}^{n}=\widehat{A}_{t}+\Phi(1-\mu) \delta\left(\widehat{Y}_{O G, t}^{n}-\widehat{Y}_{P G, t}\right),
$$

where $w=\frac{W}{P}$. Using (55), (40), and (45), at a flexible price equilibrium, the natural level of consumption, $\widehat{C}_{t}^{n}$, can be expressed as

$$
\begin{aligned}
\widehat{C}_{t}^{n}= & \frac{\left(\psi \Theta_{1}+1\right)}{\left(\psi \Theta_{1}+\sigma\right)} \widehat{A}_{t}-\frac{\left(\Phi(1-\mu) \delta+\psi \Theta_{2}\right)}{\left(\psi \Theta_{1}+\sigma\right)} \widehat{Y}_{P G, t}+\frac{\left(\Phi(1-\mu) \delta-\psi \Theta_{1}(\gamma-1)(1-\mu) \delta\right)}{\left(\psi \Theta_{1}+\sigma\right)} \widehat{Y}_{O G, t}^{n} \\
& +\frac{(1-\sigma)}{\left(\psi \Theta_{1}+\sigma\right)} \widehat{\Gamma}_{t}+\delta \widehat{T}_{A M, t}^{n}+\frac{\left(\psi \Theta_{1}(\gamma-1)(1-\mu) \delta+\psi \Theta_{2}\right)}{\left(\psi \Theta_{1}+\sigma\right)} \widehat{A}_{G, t} .
\end{aligned}
$$


Now using the demand equations at a flexible price equilibrium, the natural levels of output for the grain, vegetable and manufacturing sector can be expressed, respectively, as

$$
\begin{aligned}
\widehat{Y}_{O G, t}^{n} & =\widehat{C}_{t}^{n}-\mu \widehat{T}_{O G V, t}^{n}-(1-\delta) \widehat{T}_{A M, t}^{n} \\
\widehat{Y}_{V, t}^{n} & =\widehat{C}_{t}^{n}+(1-\mu) \widehat{T}_{O G V, t}^{n}-(1-\delta) \widehat{T}_{A M, t}^{n} \\
\widehat{Y}_{M, t}^{n} & =\widehat{C}_{t}^{n}+\delta \widehat{T}_{A M, t}^{n}
\end{aligned}
$$

where $\widehat{C}_{t}^{n}$ is given by equation (56). The aggregate natural level of output, $\widehat{Y}_{t}^{n}$, can be expressed as,

$$
\widehat{Y}_{t}^{n}=\left(1-\lambda_{c}\right) \widehat{C}_{t}^{n}+\lambda_{c}\left[\widehat{Y}_{P G, t}+\mu \widehat{T}_{O G V, t}^{n}+(1-\delta) \widehat{T}_{A M, t}^{n}\right]
$$

Equations (51) - (58) show how the presence of procurement affects the natural level of variables in the model. Procurement affects these equations as an additive shock since we assume later that procurement follows an AR(1) process. Procurement also affects these equations through the parameter, $c_{p}$, which enters into the structural coefficients in front of the variables.

\subsubsection{The Sticky price equilibrium}

We define a variable, $\widetilde{X}_{t}=\widehat{X}_{t}-\widehat{X}_{t}^{n}$, to be the deviation from the natural rate. Using equations (40), (41c) and (45) we can write $\widetilde{m c}_{M, t}$ in terms of the manufacturing sector output gap, $\left(\widehat{Y}_{M, t}-\widehat{Y}_{M, t}^{n}\right)$ :

$$
\widetilde{m c}_{M, t}=\widehat{m c}_{M, t}=\left(\psi \Theta_{1}+\sigma\right) \widetilde{Y}_{M, t}-\delta\left(\psi \Theta_{1}+\sigma-1\right) \widetilde{T}_{A M, t}
$$

Hence, the NKPC in equation (47) in the manufacturing sector becomes

$$
\begin{aligned}
\pi_{M, t} & =\beta E_{t}\left\{\pi_{M, t+1}\right\}+\lambda_{M}\left(\psi \Theta_{1}+\sigma\right) \widetilde{Y}_{M, t}-\lambda_{M} \delta\left(\psi \Theta_{1}+\sigma-1\right) \widetilde{T}_{A M, t} \\
& =\beta E_{t}\left\{\pi_{M, t+1}\right\}+\lambda_{M}\left(\psi \Theta_{1}+\sigma\right) \widetilde{C}+\lambda_{M} \delta \widetilde{T}_{A M, t} .
\end{aligned}
$$

Equation (60b) shows that inflation in the manufacturing sector sector gets affected by terms of trade changes and aggregate consumption demand. This happens because the demand for the manufacturing sector good depends on the terms of trade and the aggregate consumption demand conditions, as shown in equation (43a). Also note that the presence of procurement reduces the effect of aggregate consumption on inflation as procurement lowers the consumed part of aggregate output. Since prices are flexible in the vegetable and manufacturing sectors, no such individual NKPC exists in either sector. However, because of procurement there is a static "Phillips curve" type equation in the grain sector as can be 
seen from equation (49). Combining equation (44) and (58), we obtain

$$
\widetilde{Y}_{t}=\left(1-\lambda_{c}\right) \widetilde{C}_{t}+\lambda_{c}(1-\delta) \widetilde{T}_{A M, t}
$$

For the aggregate analysis, it is convenient to express the NKPC in terms of CPI inflation. Equations $(60 a)$ and $(61)$ with equations $(43 a-43 c),(56)$ and, $\pi_{t}-\pi_{M, t}=\delta \Delta \widehat{T}_{A M, t}$, can be rearranged to get the aggregate NKPC for the economy:

$$
\begin{aligned}
\pi_{t}= & \beta E_{t}\left\{\pi_{t+1}\right\}+\lambda_{M} \frac{\left(\psi \Theta_{1}+\sigma\right)}{\left(1-\lambda_{c}\right)} \widetilde{Y}_{t}+\lambda_{M}\left(\delta-\frac{\lambda_{c}\left(\psi \Theta_{1}+\sigma\right)(1-\delta)}{1-\lambda_{c}}\right) \widetilde{T}_{A M, t} \\
& +\delta \Delta \widehat{T}_{A M, t}-\beta \delta E_{t}\left\{\Delta \widehat{T}_{A M, t+1}\right\} .
\end{aligned}
$$

The right hand side of the equation (62) can be consolidated and written in terms of aggregate consumption and terms of trade terms as,

$$
\begin{aligned}
\pi_{t}= & \beta E_{t}\left\{\pi_{t+1}\right\}+\lambda_{M}\left(\psi \Theta_{1}+\sigma\right) \widetilde{C}_{t}+\lambda_{M} \delta \widetilde{T}_{A M, t} \\
& +\delta \Delta \widehat{T}_{A M, t}-\beta \delta E_{t}\left\{\Delta \widehat{T}_{A M, t+1}\right\}
\end{aligned}
$$

Similar to equation (60b) aggregate inflation in (63) depends on the terms of trade and aggregate consumption demand. This equation is very similar to the aggregate NKPC derived in Aoki (2001), except that the presence of procurement affects the impact that aggregate consumption has on inflation as procurement lowers the consumed part of aggregate output (as in (44)). Also, the terms of trade terms in (62) shift the Phillips curve. These terms capture the effect of terms of trade shocks on aggregate inflation.

Similarly, we derive the aggregate DIS equation by combining equations (39), (54) and (61) :

$$
\widetilde{Y}_{t}=E_{t}\left\{\widetilde{Y}_{t+1}\right\}-\frac{\left(1-\lambda_{c}\right)}{\sigma}\left[\left(\widehat{R}_{t}-E_{t}\left\{\pi_{t+1}\right\}\right)-\widehat{r}_{t}^{n}\right]-\lambda_{c}(1-\delta) E_{t}\left\{\Delta \widetilde{T}_{A M, t+1}\right\}
$$

where, $\widehat{r}_{t}^{n}=\sigma E_{t}\left\{\Delta \widehat{C}_{t+1}^{n}\right\}-(1-\sigma) E_{t}\left\{\Delta \widehat{\Gamma}_{t+1}\right\}$, is the natural rate of interest.

The NKPC and DIS equations at the aggregate level along with a monetary policy rule constitute the basis of our analysis for output and inflation dynamics.

\subsubsection{Monetary Policy Rule}

Since monetary policy follows a simple Taylor's rule with nominal interest rate as a function of aggregate inflation and economy-wide output gap, monetary policy gets affected with 
procurement policy. To capture this, we use a simple generalization of Taylor (1993):

$$
R_{t}=\left(R_{t-1}\right)^{\phi_{r}}\left(\pi_{t}\right)^{\phi_{\pi}}\left(\frac{Y_{t}}{Y_{t}^{n}}\right)^{\phi_{y}}
$$

The log-linearized version of the Taylor-rule shows that:

$$
\begin{aligned}
\widehat{R}_{t} & =\phi_{r} \widehat{R}_{t-1}+\phi_{\pi} \pi_{t}+\phi_{y}\left(\widehat{Y}_{t}-\widehat{Y}_{t}^{n}\right) \\
& =\phi_{r} \widehat{R}_{t-1}+\phi_{\pi} \pi_{t}+\phi_{y} \widetilde{Y}_{t}
\end{aligned}
$$

i.e., the nominal interest rate, $\widehat{R}_{t}$, depends on its lagged value, aggregate inflation's deviation from its target, $\pi_{t}$, and the aggregate output gap, $\widetilde{Y}_{t} .{ }^{17}$ This closes the model.

\subsection{Difference between NKPC and the DIS with and without pro- curement}

Without a procurement distortion $\left(c_{p}=0, \lambda_{c}=0\right)$, the aggregate NKPC and DIS equations in (62) and (64) respectively are:

$$
\begin{aligned}
\pi_{t} & =\beta E_{t}\left\{\pi_{t+1}\right\}+\lambda_{M}(\psi+\sigma) \widetilde{Y}_{t}+\lambda_{M} \delta \widetilde{T}_{A M, t}+\delta \Delta \widehat{T}_{A M, t}-\beta \delta E_{t}\left\{\Delta \widehat{T}_{A M, t+1}\right\} \\
\widetilde{Y}_{t} & =E_{t}\left\{\widetilde{Y}_{t+1}\right\}-\frac{1}{\sigma}\left[\left(\widehat{R}_{t}-E_{t}\left\{\pi_{t+1}\right\}\right)-\widehat{r}_{t}^{n}\right] .
\end{aligned}
$$

The presence of procurement, as can be seen from equation (64) adds a terms of trade term which shifts the DIS equation. When there is procurement, the terms of trade also shift the NKPC. Since a procurement shock shifts both the NKPC and the DIS curves, it acts as a supply shock as well as a demand shock. Moreover, we can show that when, $0 \leq \lambda_{c} \leq 1$, the slope of the DIS curve and the NKPC increases monotonically with higher values of the steady state procurement parameter, $c_{p} \cdot{ }^{18}$ In contrast, when there is no procurement the

\footnotetext{
${ }^{17}$ We assume that the inflation target is zero.

${ }^{18}$ We require the sufficient condition, $0 \leq \lambda_{c} \leq 1$, to show the following results. We first note that, $\lambda_{c}$, is given by the steady state ratio, $C / Y=1-\lambda_{c}$, which implies, $0 \leq \lambda_{c} \leq 1$. We therefore restrict the value of $c_{p}$ such that $0 \leq \lambda_{c} \leq 1$. We can show

$$
\frac{d\left(\frac{\left(\psi \Theta_{1}+\sigma\right)}{\left(1-\lambda_{c}\right)}\right)}{d c_{p}}=\frac{\left(\psi \frac{d \Theta_{1}}{d c_{p}}\right)\left(1-\lambda_{c}\right)+\left(\frac{d \lambda_{c}}{d c_{p}}\right)\left(\psi \Theta_{1}+\sigma\right)}{\left(1-\lambda_{c}\right)^{2}}>0 \forall c_{p}
$$
}

where $\frac{\left(\psi \Theta_{1}+\sigma\right)}{\left(1-\lambda_{c}\right)}$ is the slope of the NKPC which increases in $c_{p}$. Similarly, it can be shown that

$$
\frac{d\left(\frac{\sigma}{1-\lambda_{c}}\right)}{d c_{p}}=\frac{\left(\frac{d \lambda_{c}}{d c_{p}}\right) \sigma}{\left(1-\lambda_{c}\right)^{2}}>0
$$


NKPC still retains some terms of trade expressions because of the multi-sector set-up.

Suppose $\lambda_{c}>0$. An increase in the slope of the NKPC means that for a given level of the output gap, $\widetilde{Y}_{t}$, aggregate inflation, $\pi_{t}$, is higher. Moreover, in the DIS equation, (64), the response of aggregate output to a change in the real interest depends on the value of, $\sigma$, and, $\lambda_{c}$. For positive values of $c_{p}$, this responsiveness of the output gap to changes in the real interest rate becomes less, making the DIS curve steeper. This implies that to achieve a given output gap, a greater change in the real interest rate is required. The slope changes because procurement creates a wedge between the output produced and the output consumed. The changes in the real rate of interest however affects only output consumed which is a constant proportion of total output. Hence, procurement weakens monetary policy transmission since monetary transmission only applies to consumed output. Moreover, a positive steady state procurement level distorts the steady state level of all variables which makes aggregate inflation higher and the economy-wide output gap also higher.

\section{Calibration}

In this section, we calibrate the model to Indian data. ${ }^{19}$ Our goal is to understand the quantitative implications of a positive procurement shock to the economy and compare it with a negative productivity shock. We consider these two cases because they typify the kind of shocks experienced by the Indian agriculture sector. Hence, we give a single period positive procurement shock and analyze its effect on inflation, the output-gap and sectoral labor reallocation. We then contrast this with a single period negative productivity shock. We use the impulse response functions to assess implications for monetary policy set by the Reserve Bank of India, or more generally, emerging market central banks who face terms of trade shocks. In particular, we will see how a single period procurement and productivity shock affects the deviations of various variables from their steady state values.

\subsection{Description of parameters}

It is well known that the values of several structural parameters are unknown in developing and emerging market economies. Therefore, while we use some parameter estimates from the literature, we also estimate some parameters from the data. We set the discount factor for India at $\beta=.9823$ as calibrated in Levine et al. (2012). We choose the value of the inverse of Frisch elasticity of substitution, $\psi=3$ (Anand and Prasad (2010)). We fix the value of the

since $\frac{d \lambda_{c}}{d c_{p}}>0, \forall c_{p}$, where, once again, we have imposed $0 \leq \lambda_{c} \leq 1$. The slope of the DIS curve is also increasing in $c_{p}$.

${ }^{19}$ We calibrate our model using Dynare Version 4.4.2 
inter-temporal elasticity of substitution, $\sigma=1.99$, as estimated in Levine et al. (2012). ${ }^{20}$ We calculate the expenditure share on agriculture sector goods and vegetable sector goods to be, $\delta=0.52, \mu=0.44$ using household expenditure data, NSS (National Sample Survey) $68^{\text {th }}$ round (2011-2012). ${ }^{21}$ We fix the elasticity of substitution between varieties of the same sector goods $\theta=7.02$ as estimated by Levine et al. (2012). We set the measure of stickiness for manufacturing sector $\alpha_{M}=0.75$ as estimated in Levine et al. (2012) for the formal sector in India. We choose the value of $\mathrm{AR}(1)$ coefficients in equation $(50 a-50 c)$ and standard error of these regressions following Anand and Prasad (2010). ${ }^{22}$ Thus, for productivity shocks in the agriculture sector, the $\operatorname{AR}(1)$ coefficient for grain and vegetable sector is calibrated to be, $\rho_{A_{G}}=\rho_{A_{V}}=0.25$ and for manufacturing sector, $\rho_{A_{M}}=0.95$. The standard error of regression for the grain and the vegetable sector is given by, $\sigma_{A_{G}}=\sigma_{A_{V}}=0.03$, and for the manufacturing sector, $\sigma_{A_{M}}=0.02$. We estimate an $\operatorname{AR}(1)$ process on procurement in grain sector as described in equation (50d) using the procurement data published by the Ministry of Consumer Affairs (MCA), India from 1992-2012. ${ }^{23}$ We fix the interest rate smoothening parameter, $\phi_{R}=0$, initially. We put standard weights on inflation, $\phi_{\pi}=1.5$, and the output gap, $\phi_{y}=0.5$, in the Taylor Rule (Taylor (1993)). We calculate the steady state value of $c_{p}$ to be 0.08 using the annual grain production data from the RBI Indian database and

\footnotetext{
${ }^{20}$ Levine et al. (2012) estimate a closed economy DSGE model for India using Bayesian Estimation. They use data for real GDP, real investment, the GDP deflator, and the nominal interest rate for India from 1996:1 (i.e. first quarter)-2008:4 (i.e. last quarter). We use the estimated values for the 2-sector NK model from their paper.

${ }^{21}$ The household expenditure data of the NSS $68^{\text {th }}$ round (2011-12), breaks down item-wise average monthly expenditure incurred by rural and urban households (i.e., expenditures on cereals and cereal substitutes, pulses, vegetables, fruits, services, etc.). According to this round, the food expenditure share in total consumption expenditure is approximately $52.9 \%$ in rural India and $42.6 \%$ in urban India. For total household consumption expenditure, we exclude services as an item group since we don't consider services in our model. Net of services, we then sum the monthly per capita expenditure of the following items: cereals and cereal substitutes, pulses and their products, vegetables, fruits, fuel and light, clothing and footwear, and durable goods. These items proxy for consumed items in the agriculture and the manufacturing sector. The items relevant to the agriculture sector are: cereals and cereal substitutes, pulses and their products, vegetables, fruits. Summing the monthly per-capita expenditures for these items, and calculating their share in total consumption yields the parameter, $\delta$, for rural and urban households. Finally, we use the 2011 Census population weights of rural and urban households to obtain the parameter, $\delta$, as a weighted average of rural and urban agriculture consumption expenditure. Similarly, we calculate the expenditure share on vegetables as a percentage to total expenditure on agriculture sector goods, $\mu$.

${ }^{22}$ Anand and Prasad (2010) assumes persistence for a food-sector shock in an AR(1) process to be 0.25. Assuming any productivity shock to the grain sector will be same for the vegetable sector, we have set the AR(1) coefficient same for both.

${ }^{23}$ Department of Food \& Public Distribution, see http://dfpd.nic.in/. Only Wheat and Rice data is considered. We use the net procured good series. To get this we subtract the amount distributed through the public distribution system (PDS) from the procured amount every year. First we take log of this net procured good series and then demean it to get the $\widehat{Y}_{P G, t}$ series. On this series we estimate an AR(1) process to get $\rho_{Y_{P G}}=0.4$ and a standard error $\sigma_{Y_{P G}}=0.66$.
} 
procurement data from Ministry of Consumer Affairs from 1992-2012. ${ }^{24}$ We get this steady state by taking the average of the ratio of the net procured good to total production of wheat and rice. Table 1 summarizes the structural parameters used in the calibration exercise in our model.

\begin{tabular}{|c|c|c|c|}
\hline Parameter & Notation & Value & Source \\
\hline Discount factor & $\beta$ & .9823 & Levine, et al. (2012) \\
\hline Inverse of Frisch elasticity of labor supply & $\psi$ & 3 & Anand and Prasad (2012) \\
\hline $\begin{array}{l}\text { Inverse of inter-temporal elasticity } \\
\text { of substitution }\end{array}$ & $\sigma$ & 1.99 & Levine, et al. (2012) \\
\hline $\begin{array}{l}\text { Share of total consumption expenditure } \\
\text { allocated to agriculture sector goods }\end{array}$ & $\delta$ & 0.52 & Calculated by Authors \\
\hline $\begin{array}{l}\text { Share of total food consumption expenditure } \\
\text { allocated to vegetable sector goods }\end{array}$ & $\mu$ & 0.44 & Calculated by Authors \\
\hline $\begin{array}{l}\text { Elasticity of substitution between } \\
\text { the varieties of same sector goods }\end{array}$ & $\theta$ & 7.02 & Levine, et al. (2012) \\
\hline Measure of stickiness $(M)$ & $\alpha_{M}$ & 0.75 & Levine, et al. (2012) \\
\hline \multicolumn{4}{|l|}{$\operatorname{AR}(1)$ coefficients } \\
\hline Productivity shock in grain sector $(G)$ & $\rho_{A_{G}}$ & 0.25 & Anand and Prasad (2012) \\
\hline Productivity shock in vegetable sector $(V)$ & $\rho_{A_{V}}$ & 0.25 & Anand and Prasad (2012) \\
\hline Productivity shock in manufacturing sector $(M)$ & $\rho_{A_{M}}$ & 0.95 & Anand and Prasad (2012) \\
\hline Procurement in grain sector $(P G)$ & $\rho_{Y_{P G}}$ & 0.4 & Estimated by Authors \\
\hline \multicolumn{4}{|l|}{ Standard error of $\mathrm{AR}(1)$ process } \\
\hline Grain Sector $(G)$ & $\sigma_{A_{G}}$ & 0.03 & Anand and Prasad (2012) \\
\hline Vegetable Sector $(V)$ & $\sigma_{A_{V}}$ & 0.03 & Anand and Prasad (2012) \\
\hline Manufacturing Sector $(M)$ & $\sigma_{A_{M}}$ & 0.02 & Anand and Prasad (2012) \\
\hline Procurement in grain sector $(P G)$ & $\sigma_{Y_{P G}}$ & 0.66 & Estimated by Authors \\
\hline \multicolumn{4}{|l|}{ Taylor rule Parameters } \\
\hline Interest rate smoothing & $\phi_{R}$ & 0 & \\
\hline Weight on inflation gap & $\phi_{\pi}$ & 1.5 & Taylor (1993) \\
\hline Weight on output gap & $\phi_{y}$ & 0.5 & Taylor (1993) \\
\hline
\end{tabular}

Table 1: Summary of parameter values

\footnotetext{
${ }^{24}$ For production data, see https://www.rbi.org.in/Scripts/PublicationsView.aspx?id=15807
} 


\subsection{Transmission of a single period positive procurement shock in the grain sector}

Figures $2 \mathrm{a}-2 \mathrm{~d}$ plot the impulse response functions of a single period positive procurement shock, $\widehat{Y}_{P G, t}$.

\section{[ INSERT FIGURE 2a - FIGURE 2d ]}

On impact a positive procurement shock increases the markup over marginal cost, $\widehat{M C}_{G, t}$, as shown in equation (27). This increases the open grain market goods price, leading to inflation in this sector, $\pi_{O G, t}$, (see Figure $2 \mathrm{~b}$ (row 1, column 1)). At the same time this increase in the markup reduces real marginal costs in the grain sector, making firms produce more grain output, $\widehat{Y}_{G, t}$, which increases the demand for labor, $\widehat{N}_{G, t}$, (see Figure 2c (row 2, column 2) and $2 \mathrm{~d}$ (row 1, column 1)). ${ }^{25}$ The nominal wage rises in this sector because of higher labor demand and labor gets pulled out from the other two sectors as shown in Figure 2c (row 3, column 1 and 2). labor supply in the manufacturing sector, $\widehat{N}_{M, t}$, and in the vegetable sector, $\widehat{N}_{V, t}$, keep on falling till the time nominal wages equalize in all the sectors. The firms in these two sectors revise their prices upward due to higher nominal wages in their sectors and thus we observe positive inflation in, $\pi_{M, t}$ and $\pi_{V, t}$, in these two sectors as well (see Figure 2b ((row 1, column 2) and (row 2, column 1))). This is how a procurement shock gets transmitted to other sectors and leads to aggregate price inflation, $\pi_{t}$, (see Figure 2b (row 2, column 2)).

Since a procurement shock acts as a negative cost push shock to the other two sectors, the output in these two sectors, $\widehat{Y}_{M, t}$ and $\widehat{Y}_{V, t}$, fall on impact. Moreover, the manufacturing sector is a sticky price sector and thus only a fraction of firms revise their output, this creates a positive output gap, $\widetilde{Y}_{M, t}$, in this sector. At the same time the economy wide output gap, $\widetilde{Y}_{t}$, also rises as shown in Figure $2 \mathrm{~d}$ (row 3, column 3). Monetary policy responds to this increase in the inflation and the positive output gap by an increase in the nominal interest rate, $\widehat{R}_{t}$ (see equation (65)). This increase in the nominal interest rate, adjusted for a one period future expected inflation increases the real interest rate, $\widehat{r}_{t}$, as shown in Figure 2c (row 1, column 2) ${ }^{26}$ From the Euler equation (39), a rise in the real interest rate

\footnotetext{
${ }^{25}$ Note although the output of the grain sector, $\widehat{Y}_{G, t}$, increases but this increase is less than the procured quantity leading to a fall in open market grain output, $\widehat{Y}_{O G, t}$ (see Figure 2d (row 1, column 1 and 2)).

${ }^{26}$ See Taylor (1999) for a discussion of the advantages of a variety of "simple rules" over optimal interest rate rules of the following form,

$$
\widehat{R}_{t}=\widehat{r}_{t}^{n}+\phi_{\pi} \pi_{t}+\phi_{y} \widetilde{Y}_{t}
$$

where $\widehat{r}_{t}^{n}$ is the time varying natural rate of interest. We consider a "simple rule" as these rules are easy to implement by central banks. We also conducted a sensitivity analysis with the above optimal interest rate rule and our simple rule in equation (65). We find that the impact of a procurement shock on the nominal interest rate is very similar ( 0.0143 under equation (65) versus 0.0147 with the optimal interest rate rule).
} 
induces current consumption, $\widehat{C}_{t}$, to fall due to the inter-temporal substitution effect. From the demand function (equations $(43 a-43 c)$ ), the sectoral demand for goods will depend upon the income effect from falling consumption, $\widehat{C}_{t}$, and the inter-good substitution effect due to the changing terms of trade, $\widehat{T}_{A M, t}$ and $\widehat{T}_{O G V}$. As can be seen from the Figure $2 \mathrm{~d}$ ((row 1, column 2 and 3) and (row 2, column 2)), the income effect dominates and the quantity demanded falls for all three sectors in the first period using the calibrated parameters from Table $1 .{ }^{27}$

\subsection{Transmission of a single period negative productivity shock in the grain sector}

Figures $3 \mathrm{a}-3 \mathrm{c}$ plot the impulse response functions of a single period negative productivity shock, $\widehat{A}_{G, t}{ }^{28}$

\section{[ INSERT FIGURE 3a - FIGURE 3c ]}

On impact, a productivity shock reduces the grain output, $\widehat{Y}_{G, t}$, and increases the nominal marginal cost, $\widehat{M C}_{G, t}$, leading to positive inflation in the grain sector, $\pi_{O G, t}$, as shown in Figure $3 \mathrm{a}$ (row 2, column 1). A rise in the prices of the grain sector good induces consumers to shift their demand to other sector goods, $\widehat{Y}_{M, t}$ and $\widehat{Y}_{V, t}$, (see Figure 3c (row 1, column 1 and 3)). Foreseeing this rise in demand, the manufacturing and vegetable sector firms increase their output by employing more labor, $\widehat{N}_{M, t}$ and $\widehat{N}_{V, t}$. This increase in the labor demand increases the nominal wages across all sectors. The manufacturing and vegetable sector firms revise their prices upward leading to positive inflation in these two sectors, $\pi_{M, t}$ and $\pi_{V, t}$, as shown in Figure $3 \mathrm{a}(($ row 1, column 2) and (row 2, column 1)). This is how a negative productivity shock gets transmitted to other sectors and leads to aggregate price inflation, $\pi_{t}$, (see Figure 3a (row 2, column 2)).

Since a productivity shock acts as a positive demand shock to the other two sectors, the output in these two sectors, $\widehat{Y}_{M, t}$ and $\widehat{Y}_{V, t}$, rises on impact. Moreover, the manufacturing sector is a sticky price sector and thus only a fraction of firms revise their output and this creates a negative output gap, $\widetilde{Y}_{M, t}$, in this sector on impact. At the same time the economy wide output gap, $\widetilde{Y}_{t}$, also falls slightly as shown in Figure 3c(row 3, column 1). Monetary

\footnotetext{
${ }^{27}$ We have done a sensitivity analysis for different values of $\delta$ (i) arbitrarily setting it to be low $(\delta=.05)$ and high $(\delta=.70)$, and (ii) setting $\delta$ equal to the food expenditure share in total consumption in other EMEs (e.g., China (0.38), Brazil (0.24), Russia (0.30)) using data from the BRICS Joint Statistical Publication (2015). We have looked at the impulse responses of the variables for a one period positive procurement shock. A higher/lower value of $\delta$ does increase/decrease the value of inflation on impact, as would be expected. However, inflation increases at a decreasing rate as $\delta$ increases.

${ }^{28}$ For this exercise we assume no procurement distortion i.e. $\widehat{Y}_{P G, t}$ and $c_{p}$ is zero.
} 
policy responds to this increase in inflation and slightly negative output gap by an increase in the nominal interest rate, $\widehat{R}_{t}$ (see equation (65)). This increase in the nominal interest rate, adjusted for a one period future expected inflation increases the real interest rate, $\widehat{r}_{t}$, as shown in Figure 3b (row 1, column 2). From the Euler equation (39), a rise in the real interest rate induces current consumption, $\widehat{C}_{t}$, to fall due to the inter-temporal substitution effect. From the demand function (equations $(43 a-43 c)$ ), the sectoral demand for goods will depend upon the income effect from falling consumption, $\widehat{C}_{t}$, and the inter-good substitution effect due to the changing terms of trade, $\widehat{T}_{A M, t}$ and $\widehat{T}_{O G V}$. As can be seen from the Figure 3c (row1, column 1 and 3), the substitution effect dominates and the quantity demanded rises for manufacturing and vegetable sector goods in the first period using the calibrated parameters from Table 1. The main differences are summarized below in Table 2.

\begin{tabular}{l|l}
\hline One Time Positive Procurement shock & One Time Negative Productivity shock \\
\hline $\begin{array}{l}\text { 1) Increases grain sector output. } \\
\begin{array}{l}\text { 2) It acts as a negative cost push } \\
\text { shock to the other two sectors }\left(W_{t} \uparrow\right) .\end{array}\end{array}$ & $\begin{array}{l}\text { 2) It acts as a positive demand shock } \\
\text { to the other two sectors }\left(\widehat{Y}_{M, t} \uparrow \& \widehat{Y}_{V, t} \uparrow\right) .\end{array}$ \\
$\begin{array}{l}\text { 3) Leads to a positive output gap. } \\
\text { 4) Labor reallocation away from the } \\
\text { manufacturing and vegetable sectors. }\end{array}$ & $\begin{array}{l}\text { 4) Labor reallocation towards the } \\
\text { manufacturing and vegetable sectors. }\end{array}$ \\
\hline
\end{tabular}

Table 2: Main differences between a one period positive procurement shock and a one period negative productivity shock

\section{Implications for the Reserve Bank of India}

The above calibration exercise suggests that both a positive procurement shock and a negative productivity shock leads to a positive aggregate inflation and a qualitatively similar response from the central bank. As discussed above, both differ strikingly from each other in how the shock gets transmitted to the aggregate economy. Figure 4 plots the monetary policy response for a range of values of $c_{p} \in[0,0.6]$, for a common single period procurement shock $\widehat{Y}_{P G, t}$ on impact.

[ INSERT FIGURE 4 ] 
Figure 4 shows a non-linear, increasing and monotonic relation between $\widehat{R}_{t}$ and $c_{p}$. From equation (65), the nominal interest rate $\widehat{R}_{t}$ depends on aggregate inflation, $\pi_{t}$, and the aggregate output gap, $\widetilde{Y}_{t}$. A higher interest rate response of the monetary authority on impact for higher values of $c_{p}$ is thus possible if and only if higher values of $c_{p}$ leads to higher aggregate inflation or a higher aggregate output gap or both. To understand this it is important to see how $c_{p}$ changes the aggregate NKPC and DIS curves. From equation (62), and under the sufficient condition, $0<\lambda c \leq 1$, a higher value of $c_{p}$ makes the aggregate NKPC steeper which means a given output gap is now associated with higher inflation. Moreover according to the DIS equation, (64), the response of the real economy to changes in the real interest rate $\widehat{r}_{t}$ decreases with higher values of $c_{p}$, thus requiring a stronger monetary response for a given output gap. Hence the monetary policy response for a procurement shock should depend on the steady state value of $c_{p}$. This figure implies that the Reserve Bank of India should respond to changes in the terms of trade over time in a systematic way as outlined in our model, especially since the importance of food inflation in monetary policy setting over the last several years has become increasingly important (Reserve Bank of India, 2015).

\section{Conclusion}

Central banks in EMDEs such as India often grapple with understanding the inflationary impact of a shock from the agriculture sector because the precise relationship between aggregate inflation and the terms of trade may be unknown. To address this, we develop a three-sector (grain, vegetable, and manufacturing) closed economy NK-DSGE model for the Indian economy to understand how one major distortion - the procurement of grain by the government - affects overall inflationary pressures in the economy via changes in the sectoral terms of trade. Our main contribution is to identify the mechanism through which changes in the terms of trade - because of changes in procurement - leads to aggregate inflation, changes in sectoral output gaps, sectoral resource allocation, and the economy wide output gap. We then calibrate the model to India to discuss the role of monetary policy in such a setup. We show that a positive procurement shock to grain leads to higher inflation, a change in the sectoral terms of trade, and a positive output gap because of a change in the sectoral allocation of labor. We also compare the transmission of a single period positive procurement shock with a single period negative productivity shock. We consider these two cases because they typify the kind of shocks experienced by the Indian agriculture sector (upward increase in procurement, bad monsoon). For a positive productivity shock, we show that on impact, the economy experiences higher inflation, and a slightly negative output 
gap. Under a positive procurement shock, labor reallocates away from the manufacturing and the vegetable sector. Under a negative productivity shock, labor reallocates towards the manufacturing and vegetable sectors. In addition, the presence of procurement changes the standard NKPC and DIS curves of the aggregate economy. Under a sufficient condition, we show that the NKPC and DIS curves become steeper suggesting that the central bank's response to a terms of trade shock needs to be stronger. We also show that procurement weakens monetary policy transmission. We also discuss implications for monetary policy setting for the Reserve Bank of India.

Our paper contributes to a growing literature on monetary policy in India and other emerging market economies. Future work will characterize how the terms of trade influences optimal monetary policy. 


\section{References}

[1] Anand, R., \& Prasad, E.S. (2010). Optimal Price Indices for Targeting Inflation under Incomplete Markets. IMF Working Paper, 10/2000. International Monetary Fund, Washington, D.C.

[2] Anand, R., Kumar, N., \& Tulin V. (2016). Understanding India's Food Inflation: The Role of Demand and Supply Factors. IMF Working Paper, 02/2016. International Monetary Fund, Washington, D.C.

[3] Aoki, K. (2001). Optimal monetary policy responses to relative price changes. Journal of Monetary Economics, 48 (1), 55-80.

[4] Benigno, P. (2004). Optimal monetary policy in a currency area. Journal of International Economics, 63 (2), 293-320.

[5] BRICS Joint Statistical Publication (2015).

[6] Calvo, G. (1983). Staggered prices in a utility maximizing framework. Journal of Monetary Economics, 12 (3), 383-398.

[7] Carlos de R., Dib A., \& Kichian, M. (2010). Alternative Optimized Monetary Policy Rules in Multi-Sector Small Open Economies: The Role of Real Rigidities. Working Paper, 10-9. Bank of Canada.

[8] Erceg, C., \& Levin, A. (2006). Optimal monetary policy with durable consumption goods. Journal of Monetary Economics, 53 (7), 1341-1359.

[9] Galí, J., \& Monacelli T. (2005). Monetary Policy and Exchange Rate Volatility in a Small Open Economy. Review of Economic Studies, 72 (3), 707-734.

[10] Galí, J. (2008). Monetary Policy, Inflation, and the Business Cycle: An Introduction to the New Keynesian Framework. Princeton University Press.

[11] Huang, K. X. D., \& Liu, Z. (2005). Inflation targeting: what inflation rate to target? Journal of Monetary Economics, 52 (8), 1435-1462.

[12] Kaushik, B. (2011). India's Food grain Policy: An Economic Theory Perspective. Economic \& Political Weekly, Special Issue, 46 (5), 37-45.

[13] Levine, P., Vasco, G. J., Pearlman, J., \& Yang, B. (2012). An Estimated DSGE Model of the Indian Economy. In C. Ghate (Ed.), The Oxford Handbook of the Indian Economy (pp. 835-890). Oxford University Press, New York. 
[14] NSS (National Sample Survey) 68 ${ }^{\text {th }}$ Round (2011-12). Key Indicators of Household Consumer Expenditure in India. Report No. 558 (68/1.0/2).

[15] Ortega, E., \& Rebei, N. (2006). The Welfare Implications of Inflation versus Price-Level Targeting in a Two-Sector, Small Open Economy. Working Paper, 2006-12. Bank of Canada

[16] Ramaswamy, B., Seshadri, S., \& Subramanian, K.V. (2014). A Framework for Analysing Food Policy in India. Mimeo. Indian Statistical Institute, Delhi Centre.

[17] Reserve Bank of India, Annual Report (2015).

[18] Seedwell, H., Mama, A.T. , \& Tchana, F.T. (2015). Monetary policy and commodity terms of trade shocks in emerging market economies. Economic Modelling, 49, 53-71.

[19] Taylor, J. (1993). Discretion versus policy rules in practice. Carnegie-Rochester conference series on public policy, 39, 195-214.

[20] Taylor, J. (1999). Monetary Policy Rules. University of Chicago Press: Chicago, IL.

[21] Woodford, M. (2003). Interest and Prices: Foundations of a Theory of Monetary Policy. Princeton University Press. 


\section{$\begin{array}{ll}7 & \text { Figures }\end{array}$}

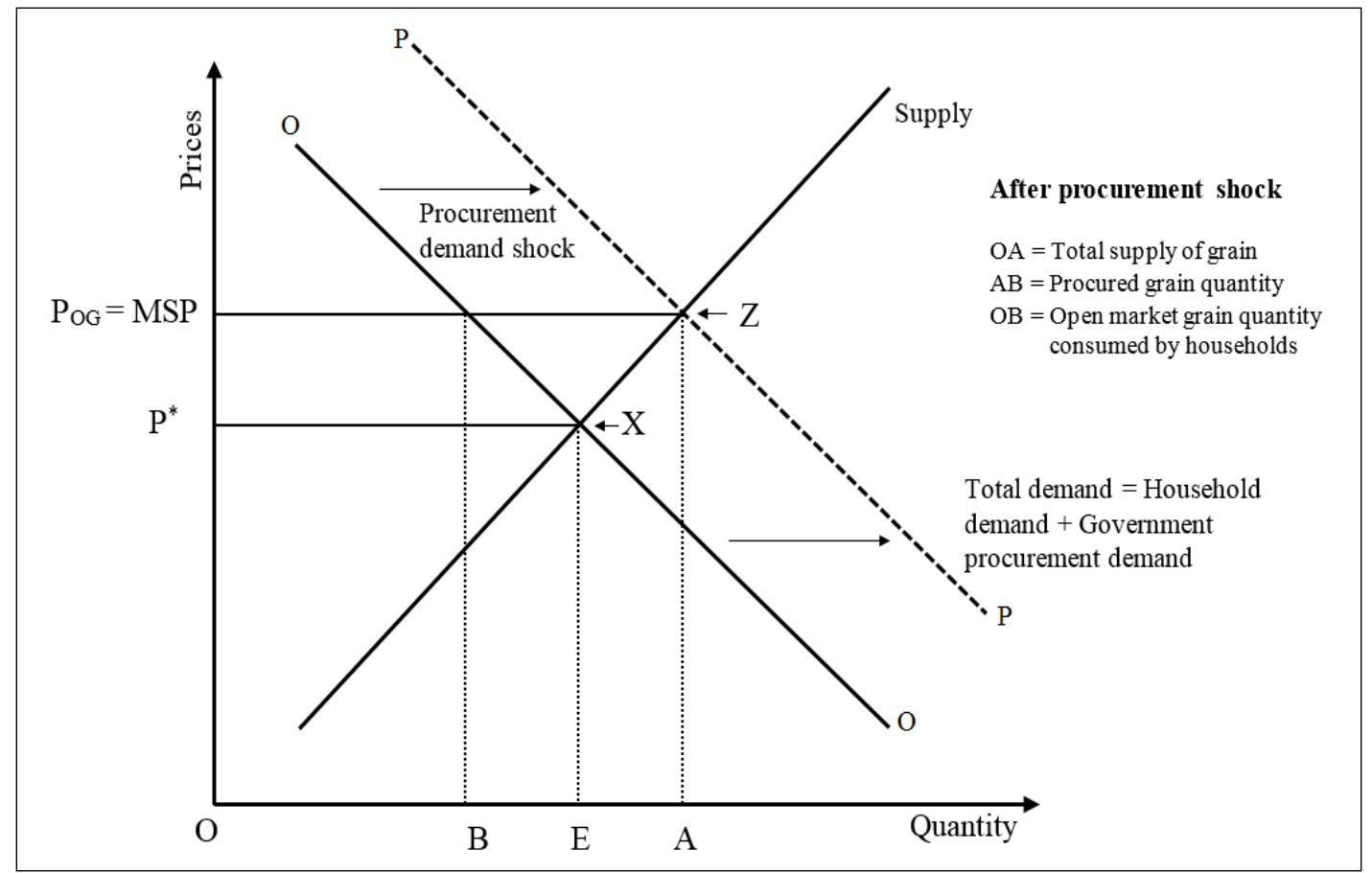

Figure 1: Effect of procurement policy on open market grain price and output. 


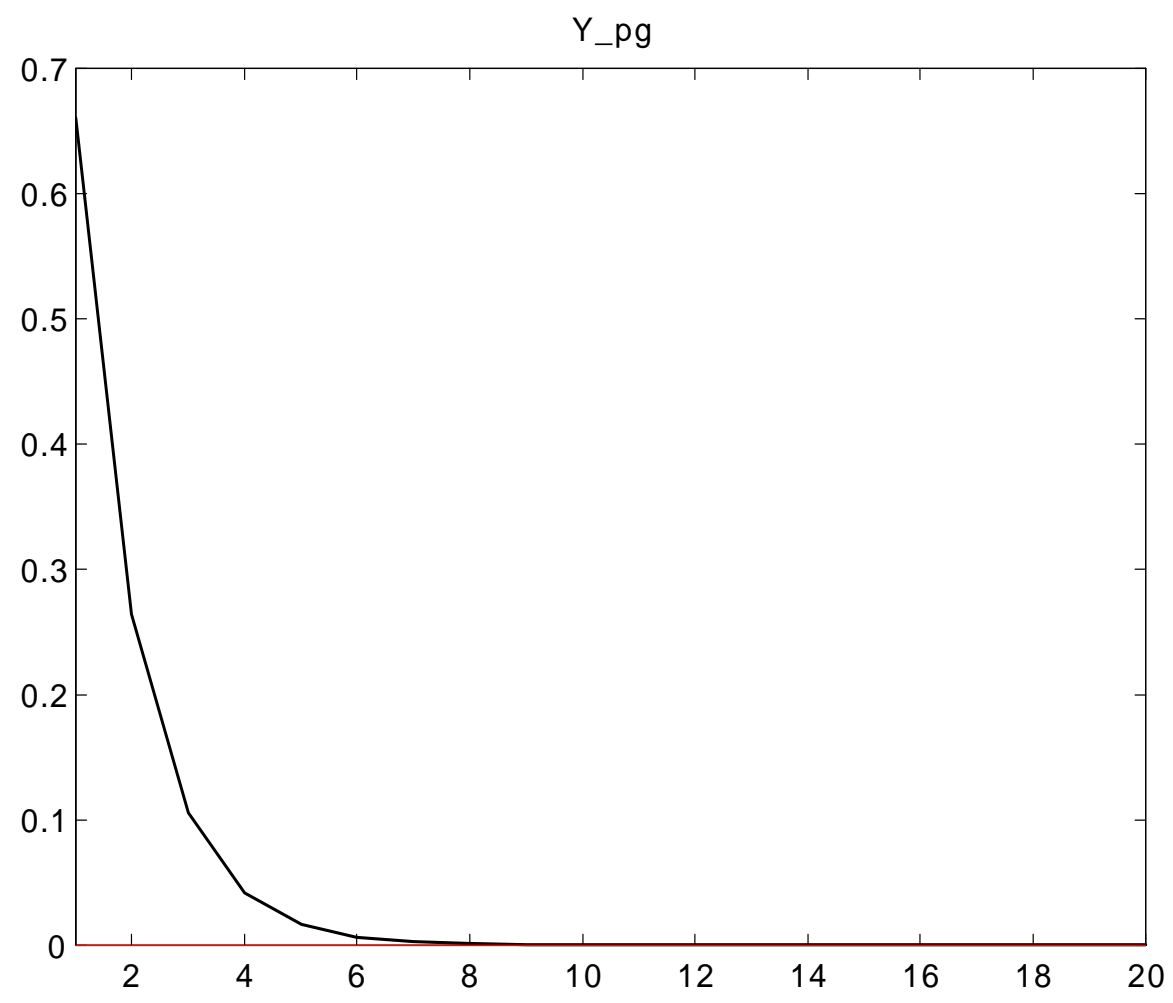

Figure 2a: Impact of a single period positive procurement $\left(\widehat{Y}_{P G, t}\right)$ shock. 

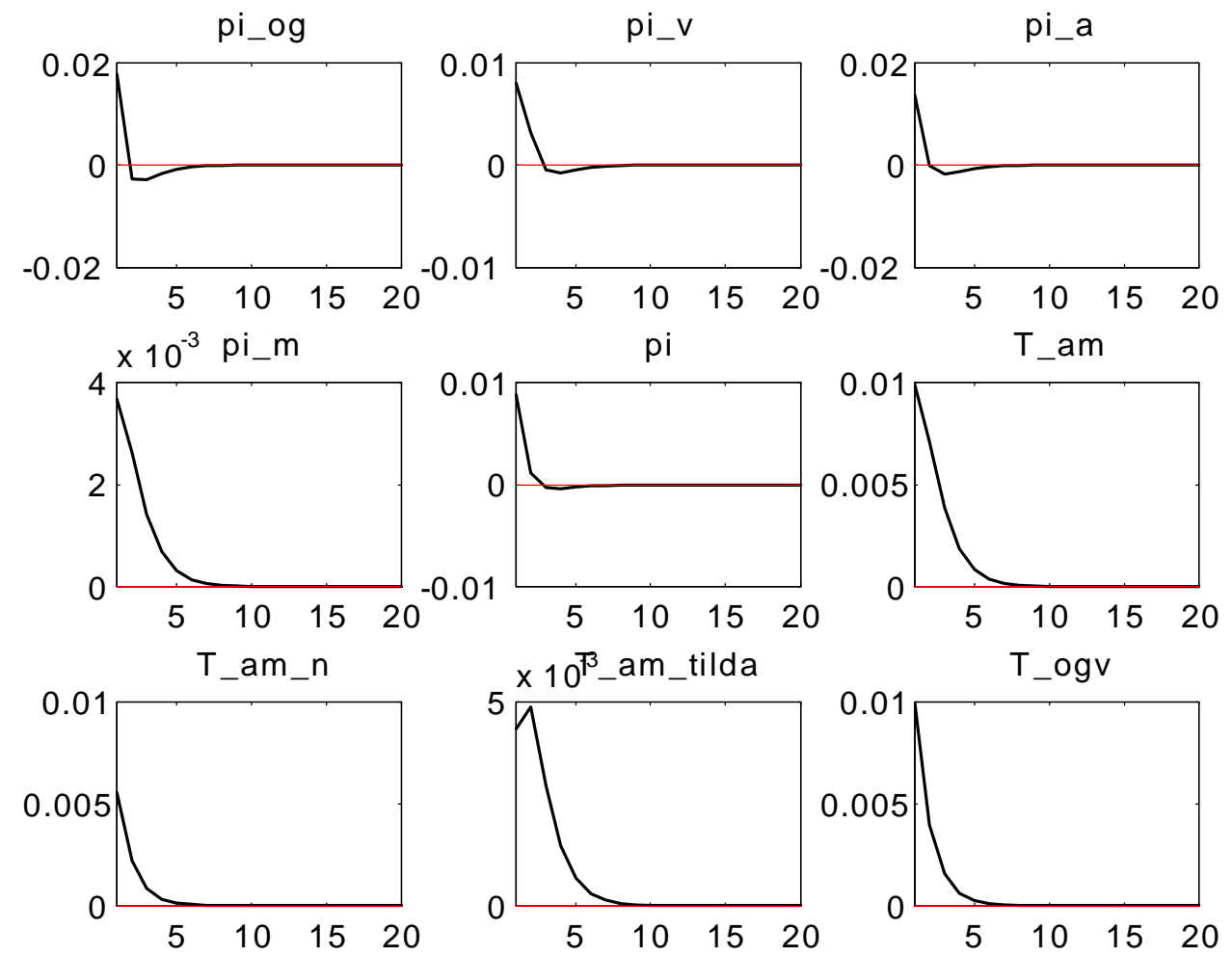

Figure 2b: Impact of a single period positive procurement $\left(\widehat{Y}_{P G, t}\right)$ shock. 

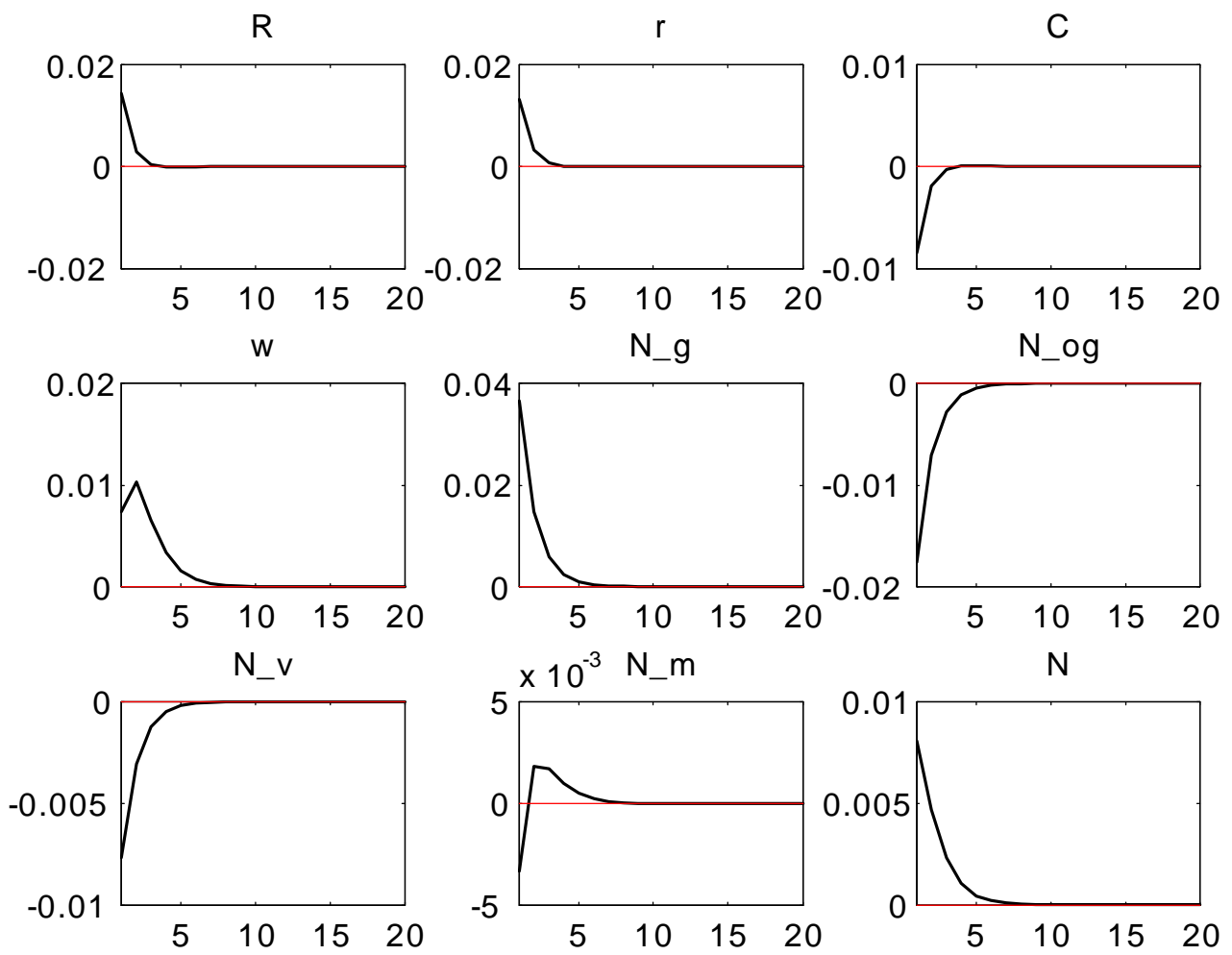

Figure 2c: Impact of a single period positive procurement $\left(\widehat{Y}_{P G, t}\right)$ shock. 

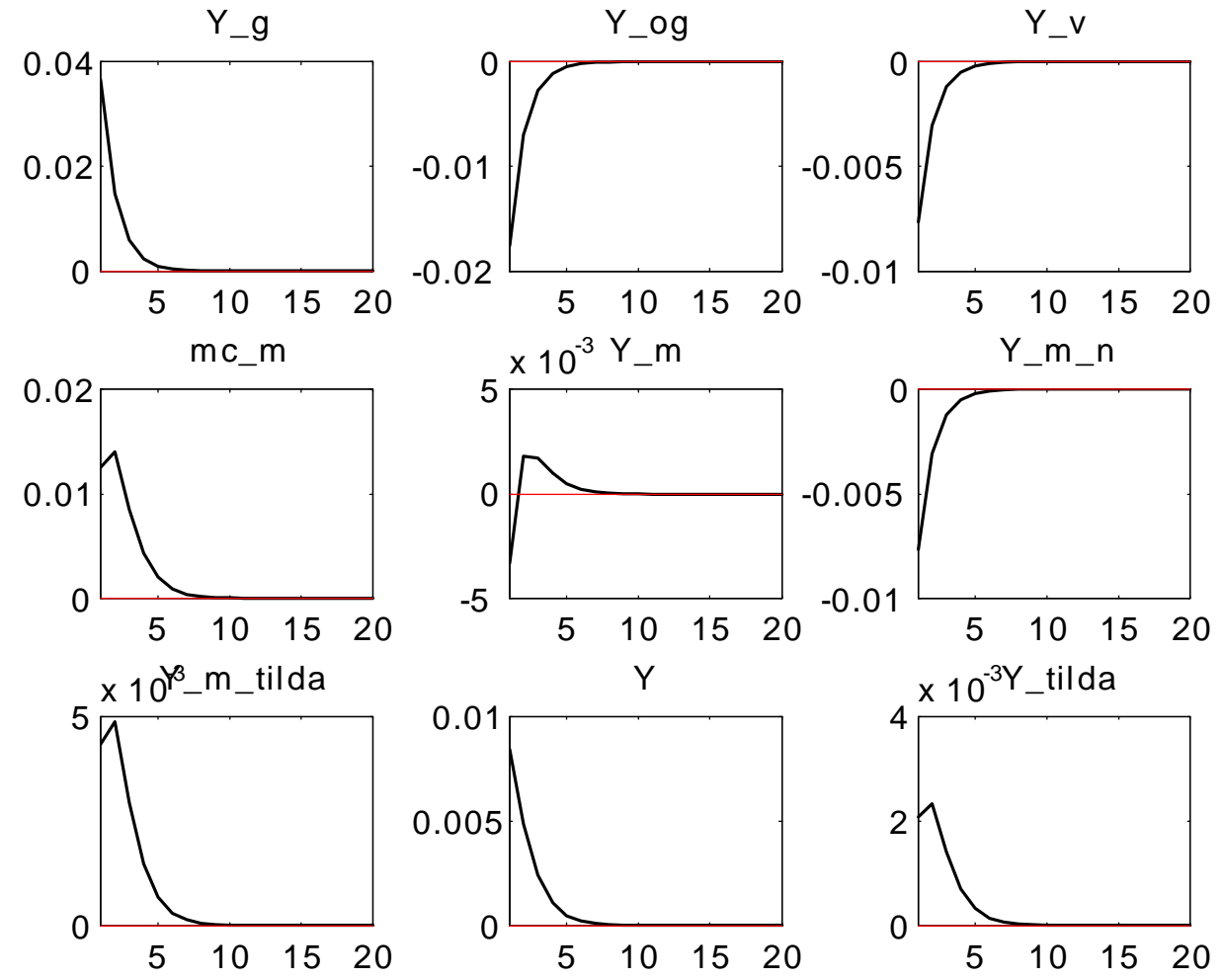

Figure 2d: Impact of a single period positive procurement $\left(\widehat{Y}_{P G, t}\right)$ shock. 

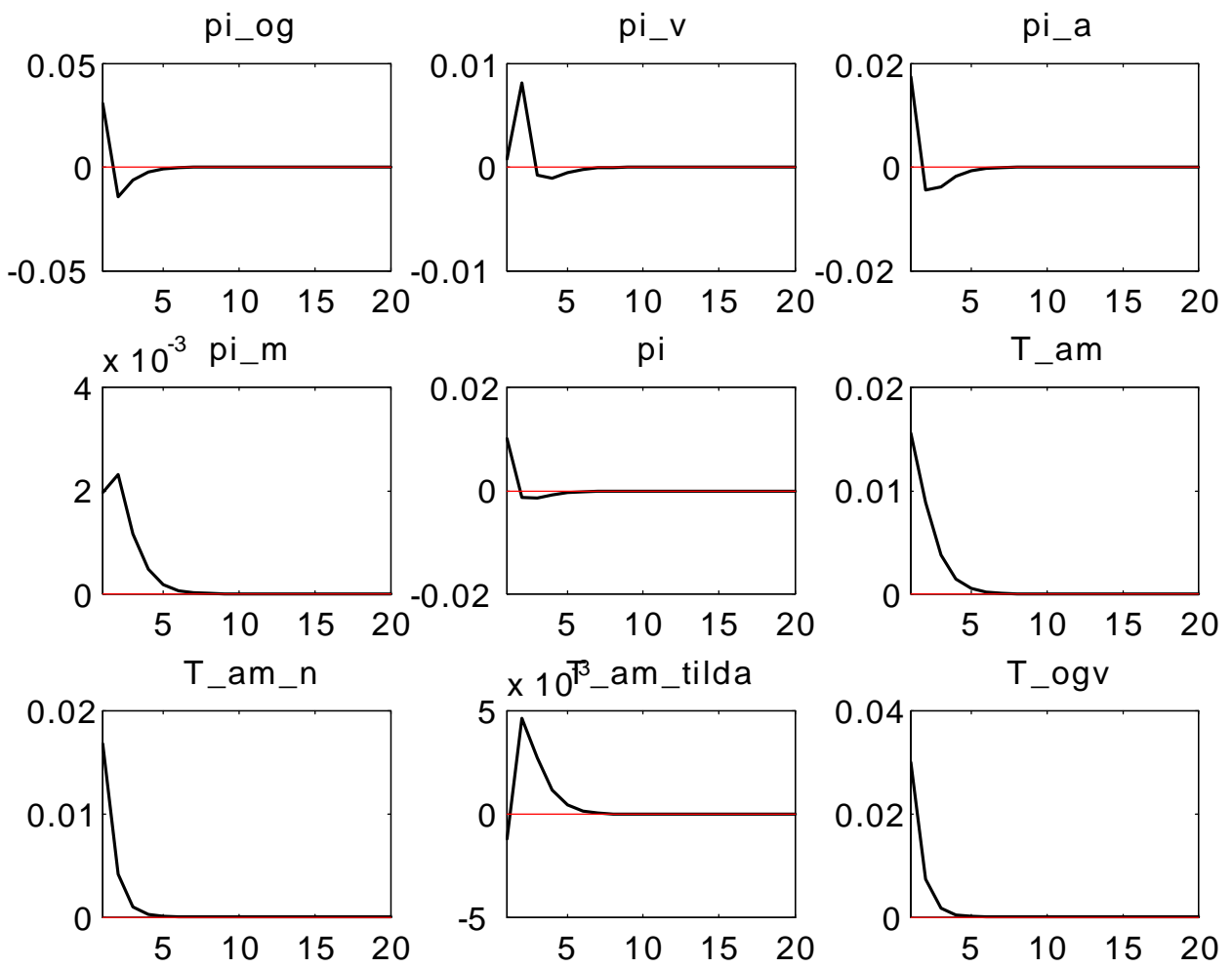

Figure 3a: Impact of a single period negative productivity $\left(\widehat{A}_{G, t}\right)$ shock. 

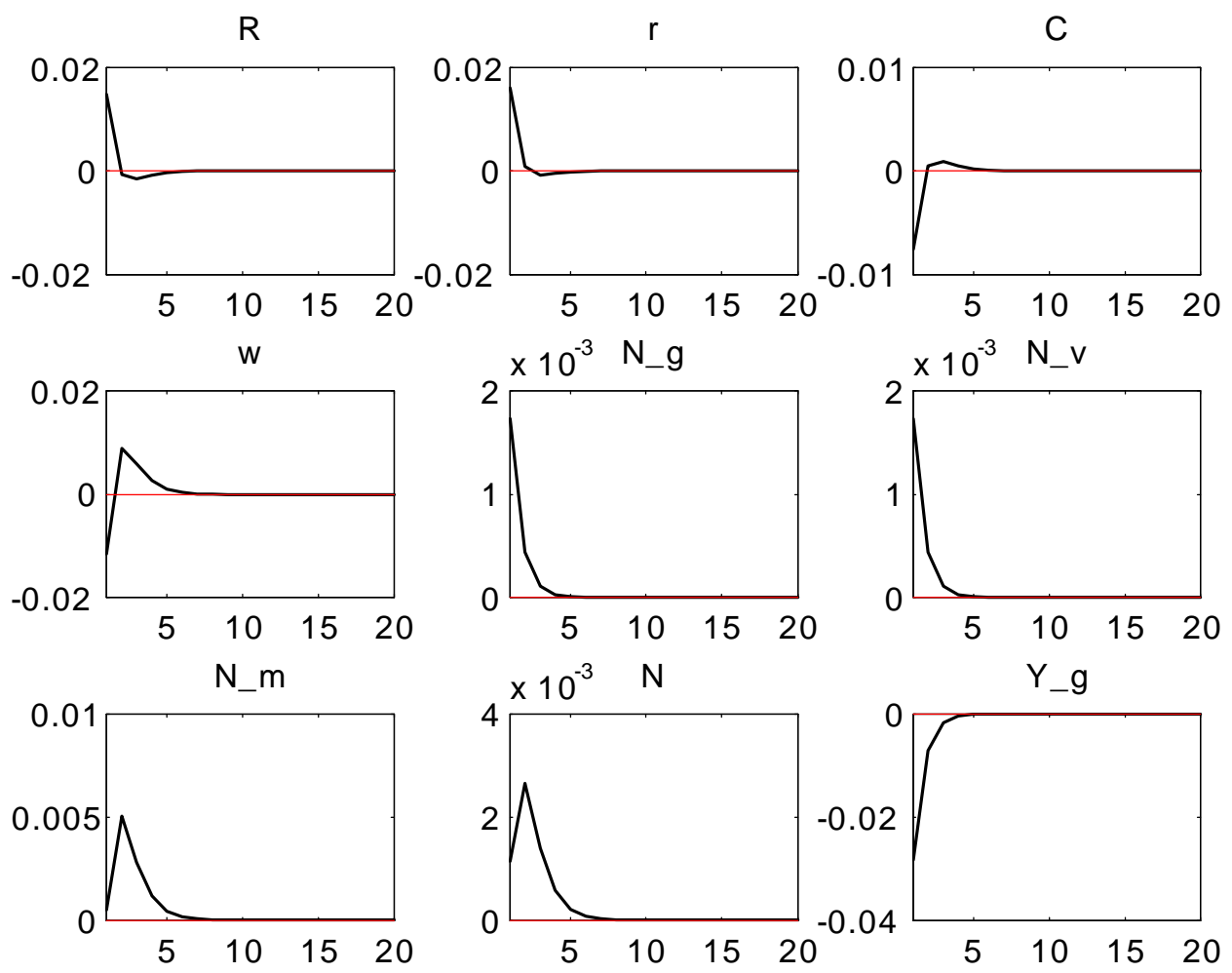

Figure 3b: Impact of a single period negative productivity $\left(\widehat{A}_{G, t}\right)$ shock. 

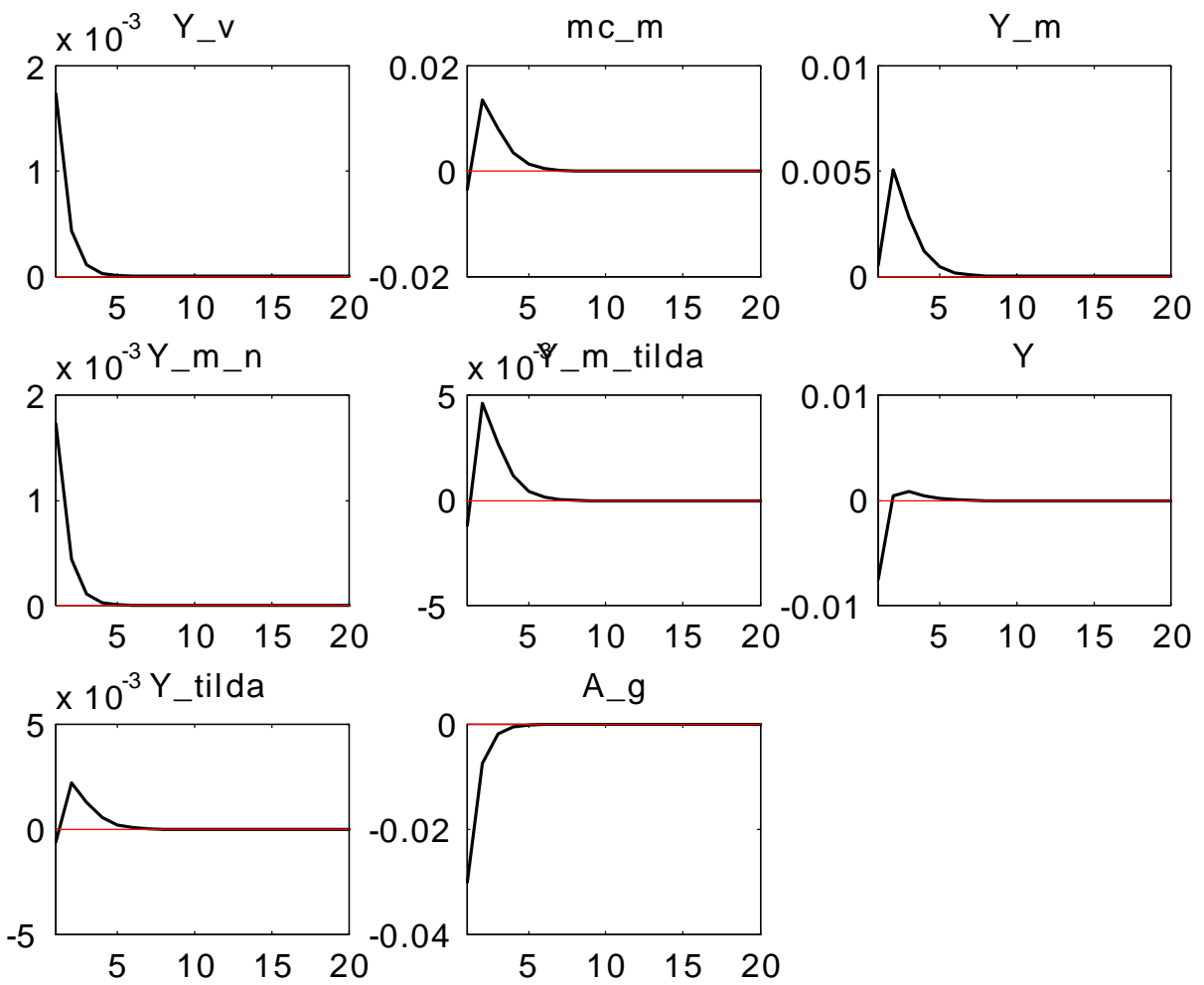

Figure 3c: Impact of a single period negative productivity $\left(\widehat{A}_{G, t}\right)$ shock. 


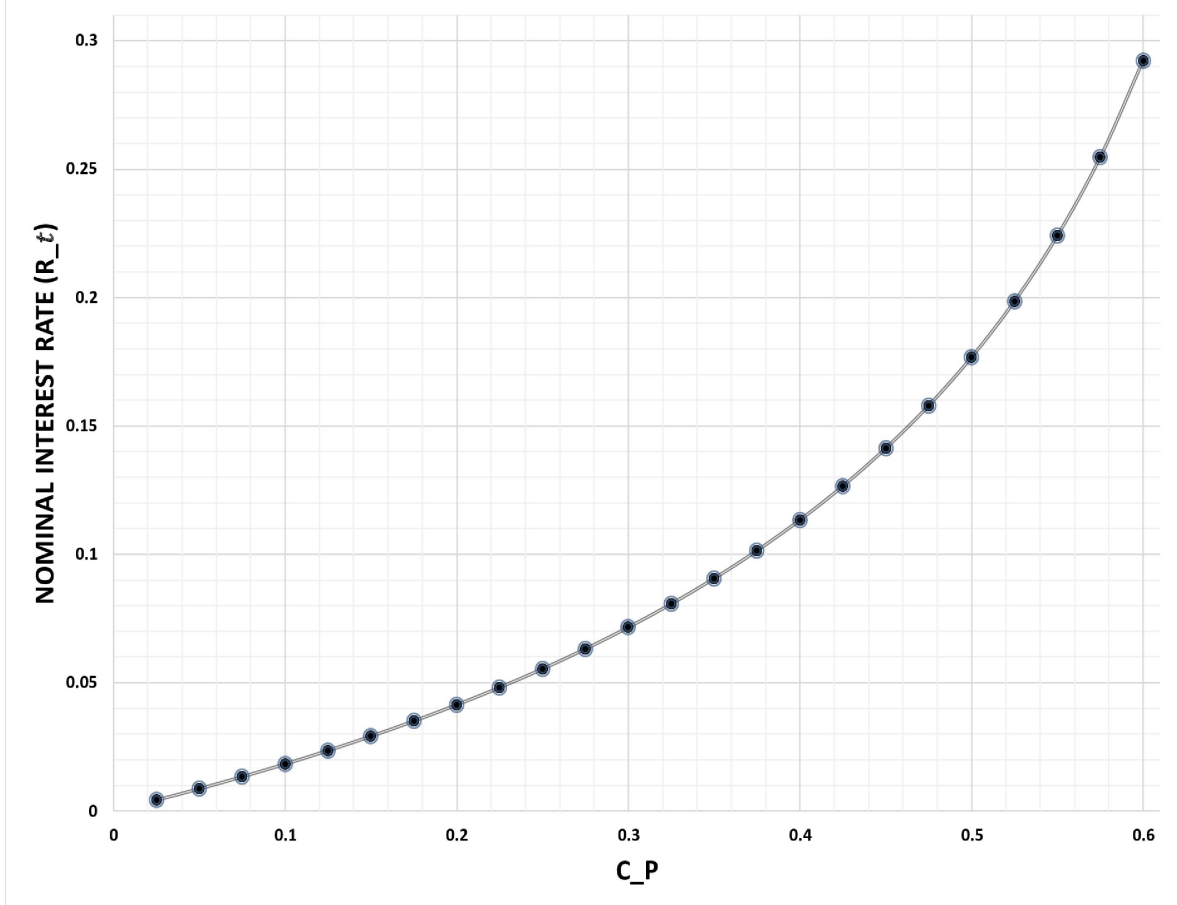

Figure 4: Monetary policy response $\left(\widehat{R}_{t}\right)$ and steady state share of procured grain $\left(c_{p}\right)$. 


\section{Technical Appendix}

- Derivation of the demand function of each variety of good $j$ : Equation (11)

$$
\begin{gathered}
\max _{C_{s, t}(j)}\left[\int_{0}^{1} C_{s, t}(j)^{\frac{\theta-1}{\theta}} d j\right]^{\frac{\theta}{\theta-1}} \text { subject to } \\
\int_{0}^{1} P_{s, t}(j) C_{s, t}(j) d j=Z_{s, t}
\end{gathered}
$$

for a given level of expenditure level, $Z_{s, t}$. The above maximization problem can be written as the following Lagrangian,

$$
\mathcal{L}=\left[\int_{0}^{1} C_{s, t}(j)^{\frac{\theta-1}{\theta}} d j\right]^{\frac{\theta}{\theta-1}}-\lambda_{t}\left(\int_{0}^{1} P_{s, t}(j) C_{s, t}(j) d j_{1}-Z_{s, t}\right)
$$

The first-order condition is given by,

$$
C_{s, t}^{\frac{1}{\theta}} C_{s, t}(j)^{-\frac{1}{\theta}}=\lambda_{t} P_{s, t}(j)
$$

for all $j \in[0,1]$. Using the above first order condition for any two varieties $j_{1}, j_{2}$ and eliminating $\lambda_{t}$ we get,

$$
C_{s, t}\left(j_{1}\right)=C_{s, t}\left(j_{2}\right)\left(\frac{P_{s, t}\left(j_{1}\right)}{P_{s, t}\left(j_{2}\right)}\right)^{-\theta}
$$

Now substituting $C_{s, t}\left(j_{1}\right)$ into $\int_{0}^{1} P_{s, t}\left(j_{1}\right) C_{s, t}\left(j_{1}\right) d j_{1}=Z_{s, t}$ and putting $\left[\int P_{s, t}\left(j_{1}\right)^{1-\theta} d j_{1}\right]^{\frac{1}{1-\theta}}=$ $P_{s, t}$, the aggregate price index of sector $s$, we get

$$
C_{s, t}\left(j_{2}\right)=\left(\frac{P_{s, t}\left(j_{2}\right)}{P_{s, t}}\right)^{-\theta} \frac{Z_{s, t}}{P_{s, t}}
$$

for all $j_{2} \in[0,1]$. Also, substituting $C_{s, t}\left(j_{1}\right)$ in $\left[\int_{0}^{1} C_{s, t}\left(j_{1}\right)^{\frac{\theta-1}{\theta}} d j_{1}\right]^{\frac{\theta}{\theta-1}}=C_{s, t}$, we get

$$
\int_{0}^{1} P_{s, t}\left(j_{2}\right) C_{s, t}\left(j_{2}\right) d j_{2}=P_{s, t} C_{s, t}=Z_{s, t}
$$

Hence $C_{s, t}(j)=\left(\frac{P_{s, t}(j)}{P_{s, t}}\right)^{-\theta} C_{s, t}$ for all $j \in[0,1]$ where $s=O G, V, M$.

- Derivation of the demand function for each sector's good: Equation(7) - (10) 
The optimization exercise is to,

$$
\begin{gathered}
\max _{\left\{C_{A, t}, C_{M, t}\right\}} \frac{\left(C_{A, t}\right)^{\delta}\left(C_{M, t}\right)^{1-\delta}}{\delta^{\delta}(1-\delta)^{(1-\delta)}} \text { subject to } \\
P_{A, t} C_{A, t}+P_{M, t} C_{M, t}=Z_{t}
\end{gathered}
$$

for a given level of expenditure level, $Z_{t}$. The above maximization problem can be written as the following Lagrangean,

$$
\mathcal{L}=\frac{\left(C_{A, t}\right)^{\delta}\left(C_{M, t}\right)^{1-\delta}}{\delta^{\delta}(1-\delta)^{(1-\delta)}}-\lambda_{t}\left(P_{A, t} C_{A, t}+P_{M, t} C_{M, t}-Z_{t}\right)
$$

The first order conditions are given by,

$$
\begin{gathered}
\frac{\delta\left(C_{A, t}\right)^{\delta-1}\left(C_{M, t}\right)^{1-\delta}}{\delta^{\delta}(1-\delta)^{(1-\delta)}}=\lambda_{t} P_{A, t} \\
\frac{(1-\delta)\left(C_{A, t}\right)^{\delta}\left(C_{M, t}\right)^{-\delta}}{\delta^{\delta}(1-\delta)^{(1-\delta)}}=\lambda_{t} P_{M, t} .
\end{gathered}
$$

Eliminating $\lambda_{t}$, we get,

$$
C_{M, t}=\frac{(1-\delta)}{\delta} C_{A, t}\left(\frac{P_{M, t}}{P_{A, t}}\right)^{-1} .
$$

Now substituting $C_{M, t}$ into $\frac{\left(C_{A, t}\right)^{\delta}\left(C_{M, t}\right)^{1-\delta}}{\delta^{\delta}(1-\delta)^{(1-\delta)}}$ and setting $\left(P_{A, t}\right)^{\delta}\left(P_{M, t}\right)^{1-\delta}=P_{t}$, the aggregate price index of the economy, we get

$$
C_{A, t}=\delta\left(\frac{P_{A, t}}{P_{t}}\right)^{-1} C_{t}
$$

Put $C_{A, t}=\delta\left(\frac{P_{A, t}}{P_{t}}\right)^{-1} C_{t}$ in $C_{M, t}$, and we get

$$
C_{M, t}=(1-\delta)\left(\frac{P_{M, t}}{P_{t}}\right)^{-1} C_{t}
$$

The above two equations can be re-written as

$$
\begin{aligned}
P_{A, t} C_{A, t} & =\delta P_{t} C_{t} \\
P_{M, t} C_{M, t} & =(1-\delta) P_{t} C_{t}
\end{aligned}
$$

Adding the above two equations we get $P_{A, t} C_{A, t}+P_{M, t} C_{M, t}=P_{t} C_{t}$. Hence $Z_{t}=P_{t} C_{t}$. 
Similarly, maximizing $\frac{\left(C_{O G, t}\right)^{(1-\mu)}\left(C_{V, t}\right)^{\mu}}{\mu^{\mu}(1-\mu)^{(1-\mu)}}$ subject to the constraint $P_{O G, t} C_{O G, t}+P_{V, t} C_{V, t}=Z_{A, t}$ we get equations (9) and (10).

- Derivation of the Euler equation and labor supply equation (13) and (14)

$$
\max _{C_{t}, N_{t}, B_{t+1}} E_{0} \sum_{t=0}^{\infty}\left[\frac{\left(\Gamma_{t} C_{t}\right)^{1-\sigma}}{1-\sigma}-\frac{\left(N_{t}\right)^{1+\psi}}{1+\psi}\right]
$$

subject to

$$
\begin{aligned}
& \int_{0}^{1} P_{O G, t}(j) C_{O G, t}(j) d j+\int_{0}^{1} P_{V, t}(j) C_{V, t}(j) d j+\int_{0}^{1} P_{M, t}(j) C_{M, t}(j) d j+E_{t}\left\{Q_{t+1} B_{t+1}\right\} \\
= & B_{t}+W_{t} N t+T_{t}+D i v_{t} .
\end{aligned}
$$

The Lagrangean for the above problem can be written as:

$$
\mathcal{L}=E_{0} \sum_{t=0}^{\infty} \beta^{t}\left\{\left[\frac{\left(\Gamma_{t} C_{t}\right)^{1-\sigma}}{1-\sigma}-\frac{\left(N_{t}\right)^{1+\psi}}{1+\psi}\right]-\lambda_{t}\left[P_{t} C_{t}+E_{t}\left\{Q_{t+1} B_{t+1}\right\}-B_{t}-W_{t} N_{t}-T_{t}-D i v_{t}\right]\right\}
$$

The first order conditions are given by:

$$
\begin{aligned}
\frac{\partial \mathcal{L}}{\partial C_{t}} & =\left(\Gamma_{t}\right)^{1-\sigma}\left(C_{t}\right)^{-\sigma}-\lambda_{t} P_{t}=0 \\
\frac{\partial \mathcal{L}}{\partial N_{t}} & =-\left(N_{t}\right)^{\psi}+\lambda_{t} W_{t}=0 \\
\frac{\partial \mathcal{L}}{\partial B_{t+1}} & =-\beta^{t} \lambda_{t} E_{t}\left\{Q_{t, t+1}\right\}+\beta^{t+1} E_{t}\left\{\lambda_{t+1}\right\}=0 .
\end{aligned}
$$

Using the first two conditions we get the labor supply equation (14), and using the first and the last condition we get Euler equation (13). In the Euler equation, $R_{t}=$ $\frac{1}{E_{t}\left\{Q_{t, t+1}\right\}}$.

- Derivation of the price setting equation: The grain sector equation(27)

The optimization problem is given by,

$$
\max _{P_{O G, t}(j)}\left\{P_{O G, t}(j)\left[Y_{O G, t}(j)+Y_{P G, t}\right]-M C_{G, t}\left[Y_{O G, t}(j)+Y_{P G, t}\right]\right\}
$$

subject to the demand constraint

$$
Y_{O G, t}(j)=\left(\frac{P_{O G, t}(j)}{P_{O G, t}}\right)^{-\theta} Y_{O G, t}
$$


The first order condition is given by:

$$
\begin{aligned}
Y_{O G, t}(j)+Y_{P G, t}+P_{O G, t}(j) \frac{\partial Y_{O G, t}(j)}{\partial P_{O G, t}(j)}-M C_{G, t} \frac{\partial Y_{O G, t}(j)}{\partial P_{O G, t}(j)}=0 . \\
\begin{aligned}
\text { Now } \frac{\partial Y_{O G, t}(j)}{\partial P_{O G, t}(j)} & =-\theta\left(\frac{P_{O G, t}(j)}{P_{O G, t}}\right)^{-\theta} \frac{1}{P_{O G, t}(j)} Y_{O G, t} \\
& =-\theta \frac{Y_{O G, t}(j)}{P_{O G, t}(j)}
\end{aligned}
\end{aligned}
$$

Simplifying we get,

$$
\begin{gathered}
Y_{O G, t}(j)+Y_{P G, t}-\theta Y_{O G, t}(j)+\theta M C_{G, t} \frac{Y_{O G, t}(j)}{P_{O G, t}(j)}=0, \\
P_{O G, t}(j)\left((1-\theta) Y_{O G, t}(j)+Y_{P G, t}\right)=-\theta M C_{G, t} Y_{O G, t}(j), \\
P_{O G, t}(j)=\frac{\theta M C_{G, t}}{\theta-1-\frac{Y_{P G, t}}{Y_{O G, t}(j)}} .
\end{gathered}
$$

Similarly one can solve for the price setting equation in the vegetable sector as given in equation (28).

- Derivation of the price setting equation: manufacturing sector equations (29) and (36)

The optimization problem is given by,

$$
\max _{P_{M, t}^{*}(j)} E_{t} \sum_{k=0}^{\infty} \alpha_{M}^{k} Q_{t, t+k}\left[P_{M, t}^{*}(j) Y_{M, t+k}(j)-M C_{M, t+k} Y_{M, t+k}(j)\right]
$$

subject to the demand constraint

$$
Y_{M, t+k}(j)=\left(\frac{P_{M, t}^{*}(j)}{P_{M, t+k}}\right)^{-\theta} Y_{M, t+k} .
$$

The first order condition is given by:

$$
E_{t} \sum_{k=0}^{\infty} \alpha_{M}^{k} Q_{t, t+k}\left[Y_{M, t+k}(j)+P_{M, t}^{*}(j) \frac{\partial Y_{M, t+k}(j)}{\partial P_{M, t}^{*}(j)}-M C_{M, t+k} \frac{\partial Y_{M, t+k}(j)}{\partial P_{M, t}^{*}(j)}\right]=0
$$




$$
\text { Now } \begin{aligned}
\frac{\partial Y_{M, t+k}(j)}{\partial P_{M, t}^{*}(j)} & =-\theta\left(\frac{P_{M, t}^{*}(j)}{P_{M, t+k}}\right)^{-\theta} \frac{1}{P_{M, t}^{*}(j)} Y_{M, t+k} \\
& =-\theta \frac{Y_{M, t+k}(j)}{P_{M, t}^{*}(j)}
\end{aligned}
$$

Simplifying we get,

$$
\begin{gathered}
E_{t} \sum_{k=0}^{\infty} \alpha_{M}^{k} Q_{t, t+k}\left[Y_{M, t+k}(j)-\theta Y_{M, t+k}(j)+\theta M C_{M, t+k} \frac{Y_{M, t+k}(j)}{P_{M, t}^{*}(j)}\right]=0, \\
P_{M, t}^{*}(j) E_{t} \sum_{k=0}^{\infty} \alpha_{M}^{k} Q_{t, t+k}(1-\theta) Y_{M, t+k}(j)=-E_{t} \sum_{k=0}^{\infty}\left(\beta \alpha_{M}\right)^{t} \theta M C_{M, t+k} Y_{M, t+k}(j), \\
P_{M, t}^{*}(j)=\frac{\theta}{\theta-1} \frac{E_{t} \sum_{k=0}^{\infty} \alpha_{M}^{k} Q_{t, t+k} Y_{M, t+k}(j) M C_{M, t+k}}{E_{t} \sum_{k=0}^{\infty} \alpha_{M}^{k} Q_{t, t+k} Y_{M, t+k}(j)} .
\end{gathered}
$$

We know that

$$
P_{M, t} \equiv\left(\int_{0}^{1} P_{M, t}(j)^{1-\theta} d j\right)^{\frac{1}{1-\theta}}
$$

is the aggregate price index of this sector. Since demand for each variety of goods in this sector is symmetric and all the firms revise their prices with a common maximization problem we can drop the ${ }^{\prime} j$ so that $P_{M, t}^{*}(j)=P_{M, t}$ for all $j$. For all the firms who do not get to choose their prices $P_{M, t}(j)=P_{M, t-1}(j)$. Hence, the aggregate price index can be written as

$$
P_{M, t}^{1-\theta}=\int_{0}^{1} P_{M, t}(j)^{1-\theta} d j=\left(1-\alpha_{M}\right)\left(P_{M, t}^{*}\right)^{1-\theta}+\alpha_{M} \int_{0}^{1} P_{M, t-1}(j)^{1-\theta} d j .
$$

Note that $\alpha_{M} \int_{0}^{1} P_{M, t-1}(j)^{1-\theta} d j$ is simply a subset of the prices in $t-1$, with each price appearing in the period $t$ distribution of unchanged prices with the same relative frequency as in the period $t-1$ price distribution (Ch-3, Woodford, 2003). Therefore,

$$
P_{M, t}=\left[\left(1-\alpha_{M}\right)\left(P_{M, t}^{*}\right)^{1-\theta}+\alpha_{M}\left(P_{M, t-1}\right)^{1-\theta}\right]^{\frac{1}{(1-\theta)}} .
$$

- Market Clearing: Derivation for equation (35). Equation (34) can be re-written 
as,

$$
\begin{aligned}
Y_{t} & =C_{t}+\frac{P_{O G, t}}{P_{t}} Y_{P G, t} \\
& =C_{t}+\frac{P_{O G, t}}{P_{A, t}} \frac{P_{A, t}}{P_{t}} Y_{P G, t} \\
& =C_{t}+\frac{P_{O G, t}}{\left(P_{O G, t}\right)^{1-\mu}\left(P_{V, t}\right)^{\mu}} \frac{P_{A, t}}{\left(P_{A, t}\right)^{\delta}\left(P_{M, t}\right)^{1-\delta}} Y_{P G, t} \\
& =C_{t}+\left(T_{O G V, t}\right)^{\mu}\left(T_{A M, t}\right)^{(1-\delta)} Y_{P G, t} .
\end{aligned}
$$

\section{- Steady states: Section 3.2}

In the steady state $Q_{t, t+k}=\beta^{k}$ (equation (13) at the steady state). Thus equations (29) and (31) in the steady state can be written as,

$$
\begin{aligned}
P_{M}^{*} & =\frac{\theta}{\theta-1} \frac{E_{t} \sum_{t=0}^{\infty}\left(\beta \alpha_{M}\right)^{t} Y_{M} M C_{M}}{E_{t} \sum_{t=0}^{\infty}\left(\beta \alpha_{M}\right)^{t} Y_{M}}, \\
& =\frac{\theta}{\theta-1} M C_{M},
\end{aligned}
$$

and

$$
\left(P_{M}\right)^{1-\theta}=\alpha_{M}\left(P_{M}\right)^{1-\theta}+\left(1-\alpha_{M}\right)\left(P_{M}^{*}\right)^{1-\theta} \text { respectively. }
$$

The above equation implies,

$$
\begin{aligned}
P_{M}^{*} & =P_{M} \\
& =\frac{\theta}{\theta-1} M C_{M}
\end{aligned}
$$

Similarly considering the price setting equation in the grain sector,

$$
P_{O G}=\frac{\theta\left(1-c_{p}\right)}{(\theta-1)\left(1-c_{p}\right)-c_{p}} M C_{G}, \text { where } c_{p}=\frac{Y_{P G}}{Y_{G}},
$$

and in the vegetable sector,

$$
P_{V}=\frac{\theta}{\theta-1} M C_{V}
$$

The aggregate price index at the steady state is:

$$
P=\left(P_{O G}\right)^{(1-\mu) \delta}\left(P_{V}\right)^{\mu \delta}\left(P_{M}\right)^{1-\delta} .
$$


Using equation(22), $M C_{s}=W$ for $s=G, V, M$, as $A_{s}=1$. Substituting these values in the above aggregate price index we get,

$$
\begin{aligned}
P & =\left(\frac{(\theta-1)\left(1-c_{p}\right)}{(\theta-1)\left(1-c_{p}\right)-c_{p}}\right)^{(1-\mu) \delta} \frac{\theta}{\theta-1} W \\
P & =\gamma^{-(1-\mu) \delta} \frac{\theta}{\theta-1} W \text { where } \gamma=\frac{(\theta-1)\left(1-c_{p}\right)-c_{p}}{(\theta-1)\left(1-c_{p}\right)}
\end{aligned}
$$

Since, $P_{M}=P_{V}=\frac{\theta}{\theta-1} W$ and $P_{O G}=\frac{\theta\left(1-c_{p}\right)}{(\theta-1)\left(1-c_{p}\right)-c_{p}} W$

$$
\begin{aligned}
\frac{P_{V}}{P} & =\frac{P_{M}}{P}=\gamma^{(1-\mu) \delta} \text { and } \\
\frac{P_{O G}}{P} & =\gamma^{(1-\mu) \delta-1} .
\end{aligned}
$$

Now from the demand functions,

$$
\begin{aligned}
\frac{C_{O G}}{C} & =\frac{(1-\mu) \delta P}{P_{O G}} \\
& =(1-\mu) \delta \gamma^{-\delta(1-\mu)+1} \\
\frac{C_{V}}{C} & =\frac{\mu \delta P}{P_{V}} \\
& =\mu \delta \gamma^{-\delta(1-\mu)}, \text { and } \\
\frac{C_{M}}{C} & =\frac{(1-\delta) P}{P_{M}} \\
& =(1-\delta) \gamma^{-\delta(1-\mu)}
\end{aligned}
$$

We can re-write the steady state labor supply equation (36) in the steady state as,

$$
\begin{aligned}
N & =N_{O G}+N_{P G}+N_{V}+N_{M} \\
& =\frac{Y_{O G}}{A_{G}}+\frac{Y_{P G}}{A_{G}}+\frac{Y_{V}}{A_{V}}+\frac{Y_{M}}{A_{M}} \\
& =C_{O G}+C_{V}+C_{M}+Y_{P G} \text { (Goods Market Equilibrium) }
\end{aligned}
$$

Using the above values from the steady state consumption demands,

$$
N=\gamma^{-\delta(1-\mu)}[1+(\gamma-1)(1-\mu) \delta] C+Y_{P G}
$$

- Derivation of the log-linearized model: Various equations in section 3.3 
Equation (39): Using a first order Taylor approximation in equation (13) yields,

$$
E_{t}\left\{\begin{array}{c}
\beta R+\beta R\left(\frac{R_{t+1}-R}{R}\right)+(1-\sigma) \beta R\left(\frac{\Gamma_{t+1}-\Gamma}{\Gamma}\right) \\
-(1-\sigma) \beta R\left(\frac{\Gamma_{t}-\Gamma}{\Gamma}\right)-\sigma \beta R\left(\frac{C_{t+1}-C}{C}\right)+\sigma \beta R\left(\frac{C_{t}-C}{C}\right) \\
+\beta R\left(\frac{C_{t}-C}{C}\right)+\beta R\left(\frac{P_{t}-P}{P}\right)-\beta R\left(\frac{P_{t+1}-P}{P}\right)
\end{array}\right\} \approx 1 .
$$

Now for variable $X_{t}, \frac{X_{t}-X}{X} \approx \ln \left(X_{t}\right)-\ln (X) \approx \widehat{X}_{t}$. Using the steady state value of Euler Equation, $\beta R=1$, we get

$$
E_{t}\left\{\widehat{R}_{t}+(1-\sigma) \widehat{\Gamma}_{t+1}-(1-\sigma) \widehat{\Gamma}_{t}-\sigma \widehat{C}_{t+1}+\sigma \widehat{C}_{t}+\widehat{P}_{t}-\widehat{P}_{t+1}\right\} \approx 0
$$

Rearranging terms and using $\widehat{P}_{t+1}-\widehat{P}_{t}=\pi_{t+1}$, we get

$$
\widehat{C}_{t}=E_{t}\left\{\widehat{C}_{t+1}\right\}-\frac{1}{\sigma}\left[\left(\widehat{R}_{t}-E_{t}\left\{\pi_{t+1}\right\}\right)+(1-\sigma) E_{t}\left\{\Delta \widehat{\Gamma}_{t+1}\right\}\right]
$$

Equation (40): Using a first order Taylor approximation in equation(14), we have

$$
\begin{aligned}
& \frac{N^{\psi}}{\Gamma^{1-\sigma} C^{-\sigma}}+\psi \frac{N^{\psi}}{\Gamma^{1-\sigma} C^{-\sigma}}\left(\frac{N_{t+1}-N}{N}\right)-(1-\sigma) \frac{N^{\psi}}{\Gamma^{1-\sigma} C^{-\sigma}}\left(\frac{\Gamma_{t}-\Gamma}{\Gamma}\right)+\sigma \frac{N^{\psi}}{\Gamma^{1-\sigma} C^{-\sigma}}\left(\frac{C_{t}-C}{C}\right) \\
\approx & \frac{W}{P}+\frac{W}{P}\left(\frac{W_{t}-W}{W}\right)-\frac{W}{P}\left(\frac{P_{t}-P}{P}\right) .
\end{aligned}
$$

This implies that,

$$
\widehat{W}_{t}-\widehat{P}_{t}=\psi \widehat{N}_{t}+\sigma \widehat{C}_{t}-(1-\sigma) \widehat{\Gamma}_{t}
$$

Equation (41a): Using a first order Taylor approximation of equation (23a), we get

$$
\begin{aligned}
& m c_{G}+m c_{G}\left(\frac{m c_{G, t}-m c_{G}}{m c_{G}}\right) \approx \frac{1}{A_{G}} \frac{W}{P}\left(T_{A M}\right)^{-(1-\delta)}\left(T_{O G V}\right)^{-\mu}-\frac{1}{A_{G}} \frac{W}{P}\left(T_{A M}\right)^{-(1-\delta)}\left(T_{O G V}\right)^{-\mu} \\
& {\left[\left(\frac{A_{G, t}-A_{G}}{A_{G}}\right)+\left(\frac{W_{t}-W}{W}\right)-\left(\frac{P_{t}-P}{P}\right)-(1-\delta)\left(\frac{T_{A M, t}-T_{A M}}{T_{A M}}\right)-\mu\left(\frac{T_{O G, V, t}-T_{O G, V}}{T_{O G, V}}\right)\right]}
\end{aligned}
$$

Simplifying the above expression using the steady state expression,

$$
\begin{aligned}
& m c_{G}=\frac{1}{A_{G}} \frac{W}{P}\left(T_{A M}\right)^{-(1-\delta)}\left(T_{O G V}\right)^{-\mu} \text {, we get } \\
& \qquad \widehat{m c}_{G, t}=\widehat{W}_{t}-\widehat{P}_{t}-\widehat{A}_{G, t}-(1-\delta) \widehat{T}_{A M, t}-\mu \widehat{T}_{O G V, t} .
\end{aligned}
$$

Similarly we can derive $(41 b)$ and $(41 c)$. 
Log-linearized sectoral employment can be obtained by taking a first order Taylor approximation of equation (26) and noting that $N_{G, t}=\frac{1}{A_{G, t}}\left\{Y_{P G, t}+Y_{O G, t} Z_{O G, t}\right\}$, where a first order approximation to the dispersion term, $\widehat{Z}_{s, t} \approx 0$. (For details see Gali (2003), Ch-3)

- Note that:

$$
\begin{aligned}
\frac{P_{t}}{P_{A, t}} & =\frac{\left(P_{A, t}\right)^{\delta}\left(P_{M, t}\right)^{1-\delta}}{P_{A, t}}=\left(\frac{P_{A, t}}{P_{M, t}}\right)^{-(1-\delta)}=\left(T_{A M, t}\right)^{-(1-\delta)} \\
\frac{P_{t}}{P_{M, t}} & =\frac{\left(P_{A, t}\right)^{\delta}\left(P_{M, t}\right)^{1-\delta}}{P_{M, t}}=\left(\frac{P_{A, t}}{P_{M, t}}\right)^{\delta}=\left(T_{A M, t}\right)^{\delta} \\
\frac{P_{A, t}}{P_{O G, t}} & =\frac{\left(P_{O G, t}\right)^{1-\mu}\left(P_{V, t}\right)^{\mu}}{P_{O G, t}}=\left(\frac{P_{O G, t}}{P_{V, t}}\right)^{-\mu}=\left(T_{O G V, t}\right)^{-\mu} \\
\frac{P_{A, t}}{P_{V, t}} & =\frac{\left(P_{O G, t}\right)^{1-\mu}\left(P_{V, t}\right)^{\mu}}{P_{V, t}}=\left(\frac{P_{O G, t}}{P_{V, t}}\right)^{1-\mu}=\left(T_{O G V, t}\right)^{1-\mu} .
\end{aligned}
$$

We the above four equations to re-write the demand functions $C_{O G, t}, C_{M, t}, C_{V, t}$ in terms of $C_{t}$ and the terms of trade terms $\left(T_{A M, t} \& T_{O G V, t}\right)$. Using the goods market equilibrium and the demand functions it is easy to derive equations $(43 a)-(43 c)$ using a first order Taylor's approximation. Log linearization of the aggregate goods market clearing equation (35), gives us,

$$
\begin{aligned}
& Y+Y \frac{\left(Y_{t}-Y\right)}{Y} \approx C+\left(T_{O G V}\right)^{\mu}\left(T_{A M}\right)^{1-\delta} Y_{P G}+\frac{\left(C_{t}-C\right)}{C} C \\
&+\mu\left(T_{O G V}\right)^{\mu-1}\left(T_{A M}\right)^{1-\delta} Y_{P G} \frac{\left(T_{O G V, t}-T_{O G V}\right)}{T_{O G V}} T_{O G V} \\
&+(1-\delta)\left(T_{O G V}\right)^{\mu}\left(T_{A M}\right)^{-\delta} Y_{P G} \frac{\left(T_{A M, t}-T_{A M}\right)}{T_{A M}} T_{A M} \\
&+\left(T_{O G V}\right)^{\mu}\left(T_{A M}\right)^{1-\delta} \frac{\left(Y_{P G, t}-Y_{P G}\right)}{Y_{P G}} Y_{P G} \\
& \widehat{Y}_{t}=\frac{C}{Y} \widehat{C}_{t}+\frac{\left(T_{O G V}\right)^{\mu}\left(T_{A M}\right)^{1-\delta} Y_{P G}}{Y}\left[\mu \widehat{T}_{O G V, t}+(1-\delta) \widehat{T}_{A M, t}+\widehat{Y}_{P G, t}\right]
\end{aligned}
$$

Note $\frac{\left(T_{O G V}\right)^{\mu}\left(T_{A M}\right)^{1-\delta} Y_{P G}}{Y}=\frac{\gamma^{-\mu} \gamma^{-(1-\mu)(1-\delta)}}{Y} Y_{P G}=\gamma^{[\delta(1-\mu)-1]} c_{p} s_{g}=\lambda_{c}$ and $\frac{C}{Y}=1-\lambda_{c}$

$$
\therefore \widehat{Y}_{t}=\left(1-\lambda_{c}\right) \widehat{C}_{t}+\lambda_{c}\left[\mu \widehat{T}_{O G V, t}+(1-\delta) \widehat{T}_{A M, t}+\widehat{Y}_{P G, t}\right] \text {. }
$$


- Equation (36) can be written as,

$$
\begin{aligned}
& N_{t}=N_{O G, t}+N_{P G, t}+N_{V, t}+N_{M, t}, \\
& N_{t}=\frac{Y_{O G, t}}{A_{G}}+\frac{Y_{P G, t}}{A_{G}}+\frac{Y_{V, t}}{A_{V, t}}+\frac{Y_{M, t} Z_{M, t}}{A_{M, t}} .
\end{aligned}
$$

Log linearizing Equation (36), we get

$$
\begin{aligned}
N+N\left(\frac{N_{t}-N}{N}\right) \approx & \frac{Y_{O G}}{A_{G}}+\frac{Y_{P G}}{A_{G}}+\frac{Y_{V}}{A_{V}}+\frac{Y_{M}}{A_{M}}+\frac{Y_{O G}}{A_{G, t}}\left[\left(\frac{Y_{O G, t}-Y_{O G}}{Y_{O G}}\right)-\left(\frac{A_{G, t}-A_{G}}{A_{G}}\right)\right] \\
& +\frac{Y_{P G}}{A_{G, t}}\left[\left(\frac{Y_{P G, t}-Y_{P G}}{Y_{P G}}\right)-\left(\frac{A_{G, t}-A_{G}}{A_{G}}\right)\right] \\
& +\frac{Y_{V}}{A_{V}}\left[\left(\frac{Y_{V, t}-Y_{V}}{Y_{V}}\right)-\left(\frac{A_{V, t}-A_{V}}{A_{V}}\right)\right] \\
& +\frac{Y_{M} Z_{M}}{A_{M, t}}\left[\left(\frac{Y_{M, t}-Y_{M}}{Y_{M}}\right)+\left(\frac{Z_{M, t}-Z_{M}}{Z_{M}}\right)-\left(\frac{A_{M, t}-A_{M}}{A_{M}}\right)\right] .
\end{aligned}
$$

Using $Z_{M}=1$ and $\widehat{Z}_{M, t} \approx 0$ (as shown in Gali (2008)), we get

$$
\begin{aligned}
& N \widehat{N}_{t}=Y_{O G}\left(\widehat{Y}_{O G, t}-\widehat{A}_{G, t}\right)+Y_{P G}\left(\widehat{Y}_{P G, t}-\widehat{A}_{G, t}\right)+Y_{V}\left(\widehat{Y}_{V, t}-\widehat{A}_{V, t}\right)+Y_{M}\left(\widehat{Y}_{M, t}-\widehat{A}_{M, t}\right) \\
& N \widehat{N}_{t}=C_{O G}\left(\widehat{C}_{O G, t}-\widehat{A}_{G, t}\right)+Y_{P G}\left(\widehat{Y}_{P G, t}-\widehat{A}_{G, t}\right)+C_{V}\left(\widehat{C}_{V, t}-\widehat{A}_{V, t}\right)+C_{M}\left(\widehat{C}_{M, t}-\widehat{A}_{M, t}\right) .
\end{aligned}
$$

Using steady state equations $(37 a)-(37 b)$ in section 3.2 , we get

$$
\begin{aligned}
N \widehat{N}_{t}= & \gamma^{-\delta(1-\mu)}\left[(1-\mu)(\gamma-1) \delta\left(\widehat{C}_{O G, t}-\widehat{A}_{G, t}\right)+\mu \delta\left(\widehat{C}_{V, t}-\widehat{A}_{V, t}\right)+(1-\delta)\left(\widehat{C}_{M, t}-\widehat{A}_{M, t}\right)\right] \\
& +Y_{P G}\left(\widehat{Y}_{P G, t}-\widehat{A}_{G, t}\right) \\
N \widehat{N}_{t}= & \gamma^{-\delta(1-\mu)}\left[\widehat{C}_{t}-\widehat{A}_{t}+(1-\mu)(\gamma-1) \delta\left(\widehat{Y}_{O G, t}-\widehat{A}_{G, t}\right)\right] C+Y_{P G}\left(\widehat{Y}_{P G, t}-\widehat{A}_{G, t}\right) \\
\text { where } \widehat{C}_{t}= & (1-\mu) \delta \widehat{C}_{O G, t}+\mu \delta \widehat{C}_{V, t}+(1-\delta) \widehat{C}_{M, t} \\
\widehat{A}_{t}= & (1-\mu) \delta \widehat{A}_{G, t}+\mu \delta \widehat{A}_{V, t}+(1-\delta) \widehat{A}_{M, t} .
\end{aligned}
$$

Using equation(38),

$$
\widehat{N}_{t}=\frac{\gamma^{-\delta(1-\mu)}\left[\widehat{C}_{t}-\widehat{A}_{t}+(1-\mu)(\gamma-1) \delta\left(\widehat{Y}_{O G, t}-\widehat{A}_{G, t}\right)\right] C+Y_{P G}\left(\widehat{Y}_{P G, t}-\widehat{A}_{G, t}\right)}{\gamma^{-\delta(1-\mu)}[1+(1-\mu)(\gamma-1) \delta] C+Y_{P G}} .
$$


Using (35) at the steady state, $Y=C+\frac{P_{O G}}{P} Y_{P G}$,

$$
\begin{aligned}
& \frac{Y_{P G}}{C}=\frac{Y_{P G}}{Y-\gamma^{[\delta(1-\mu)-1]} Y_{P G}}=\frac{\frac{Y_{P G}}{Y_{G}}}{\frac{Y-\gamma^{[\delta(1-\mu)-1] Y_{P G}}}{Y_{G}}} \\
& =\frac{c_{p} s_{g}}{1-\gamma^{[\delta(1-\mu)-1]} c_{p} s_{g}} \text { where } s_{g}=\frac{Y_{G}}{Y}, c_{p}=\frac{Y_{P G}}{Y_{G}} \text {. } \\
& \widehat{N}_{t}=\frac{\left(1-\gamma^{[\delta(1-\mu)-1]} c_{p} s_{g}\right) \gamma^{-\delta(1-\mu)}\left[\widehat{C}_{t}-\widehat{A}_{t}+(1-\mu)(\gamma-1) \delta\left(\widehat{Y}_{O G, t}-\widehat{A}_{G, t}\right)\right]}{\gamma^{-\delta(1-\mu)}[1+(1-\mu) \delta \gamma]\left(1-\gamma^{[\delta(1-\mu)-1]} c_{p} s_{g}\right)+c_{p} s_{g}} \\
& +\frac{c_{p} s_{g}\left(\widehat{Y}_{P G, t}-\widehat{A}_{G, t}\right)}{\gamma^{-\delta(1-\mu)}[1+(1-\mu) \delta \gamma]\left(1-\gamma^{[\delta(1-\mu)-1]} c_{p} s_{g}\right)+c_{p} s_{g}} . \\
& \widehat{N}_{t}=\Theta_{1}\left[\widehat{C}_{t}-\widehat{A}_{t}+(1-\mu)(\gamma-1) \delta\left(\widehat{Y}_{O G, t}-\widehat{A}_{G, t}\right)\right]+\Theta_{2}\left(\widehat{Y}_{P G, t}-\widehat{A}_{G, t}\right) \\
& \text { where } \Theta_{1}=\frac{\left(1-\gamma^{[\delta(1-\mu)-1]} c_{p} s_{g}\right) \gamma^{-\delta(1-\mu)}}{\gamma^{-\delta(1-\mu)}[1+(1-\mu)(\gamma-1) \delta]\left(1-\gamma^{[\delta(1-\mu)-1]} c_{p} s_{g}\right)+c_{p} s_{g}} \\
& \Theta_{2}=\frac{c_{p} s_{g}}{\gamma^{-\delta(1-\mu)}[1+(1-\mu)(\gamma-1) \delta]\left(1-\gamma^{[\delta(1-\mu)-1]} c_{p} s_{g}\right)+c_{p} s_{g}} .
\end{aligned}
$$

- Equation (47) is the New-Keynesian Phillips Curve for the manufacturing sector derived by log-linearizing (29) and (31) (for details see Gali (2008) Ch-3).

- Equation (51) : Log-linearizing real marginal cost, $m c_{G, t}$, as in (27), and using a first order Taylor approximation we get

$$
m c_{G, t}=\frac{\theta-1}{\theta}-\frac{Y_{P G, t}}{\theta Y_{O G, t}}
$$




$$
\begin{aligned}
m c_{G}+m c_{G}\left(\frac{m c_{G, t}-m c_{G}}{m c_{G}}\right) \approx & \frac{\theta-1}{\theta}-\frac{Y_{P G}}{\theta Y_{O G}}+\frac{Y_{P G}}{\theta Y_{O G}}\left(\frac{Y_{O G, t}-Y_{O G}}{Y_{O G}}\right) \\
& -\frac{Y_{P G}}{\theta Y_{O G}}\left(\frac{Y_{P G, t}-Y_{P G}}{Y_{P G}}\right) \\
m c_{G} \widehat{m c}_{G, t}= & \frac{Y_{P G}}{\theta Y_{O G}} \widehat{Y}_{O G, t}-\frac{Y_{P G}}{\theta Y_{O G}} \widehat{Y}_{P G, t} \\
\widehat{m c}_{G, t}= & \Phi\left(\widehat{Y}_{O G, t}-\widehat{Y}_{P G, t}\right) \text { where } \Phi=\frac{c_{p}}{(\theta-1)\left(1-c_{p}\right)-c_{p}} .
\end{aligned}
$$

From (28) the real marginal cost $(V)$ is a constant and hence $\widehat{m c}_{V, t}=0$.

- Derivation of the flexible price equilibrium: The natural level of a variable is the flexible price equilibrium level. The natural level of the terms of trade in equation (52) and (53) can be derived as (for Equation (52))

$$
\begin{aligned}
T_{O G V, t}^{n} & =\frac{P_{O G, t}}{P_{V, t}}=\frac{\frac{M C_{G, t}}{m c_{G, t}}}{\frac{M C_{V, t}}{m c_{V, t}}}=\frac{\frac{W_{t}}{m c_{G, t} A_{G, t}}}{\frac{W_{t}}{m c_{G, t} A_{V, t}}} \\
& =\frac{m c_{V, t}}{m c_{G, t}} \frac{A_{V, t}}{A_{G, t}}, \\
\widehat{T}_{O G V, t}^{n} & =\widehat{m c}_{V, t}-\widehat{m c}_{G, t}+\widehat{A}_{V, t}-\widehat{A}_{G, t} \\
& =-\Phi\left(\widehat{Y}_{O G, t}^{n}-\widehat{Y}_{P G, t}\right)+\widehat{A}_{V, t}-\widehat{A}_{G, t} .
\end{aligned}
$$

Similarly $\widehat{T}_{A M, t}^{n}$ can be derived. For $\widehat{w}_{t}^{n}$ consider first the aggregate price index, $P_{t}^{n}$,

$$
\begin{aligned}
P_{t}^{n} & =\left(P_{A, t}^{n}\right)^{\delta}\left(P_{M, t}^{n}\right)^{1-\delta}=\left(P_{O G, t}^{n}\right)^{(1-\mu) \delta}\left(P_{V, t}^{n}\right)^{\mu \delta}\left(P_{M, t}^{n}\right)^{1-\delta} \\
& =\left(\frac{M C_{G, t}^{n}}{m c_{G, t}^{n}}\right)^{(1-\mu) \delta}\left(\frac{M C_{V, t}^{n}}{m c_{V, t}^{n}}\right)^{\mu \delta}\left(\frac{M C_{M, t}^{n}}{m c_{M, t}^{n}}\right)^{1-\delta} \\
& =\left(\frac{W_{t}^{n}}{A_{G, t} m c_{G, t}^{n}}\right)^{(1-\mu) \delta}\left(\frac{W_{t}^{n}}{A_{V, t} m c_{V, t}^{n}}\right)^{\mu \delta}\left(\frac{W_{t}^{n}}{A_{M, t} m c_{M, t}^{n}}\right)^{1-\delta} \\
& =\frac{W_{t}^{n}}{\left(A_{G, t} m c_{G, t}^{n}\right)^{(1-\mu) \delta}\left(A_{V, t} m c_{V, t}^{n}\right)^{\mu \delta}\left(A_{M, t} m c_{M, t}^{n}\right)^{1-\delta}}=\frac{W_{t}^{n}}{A_{t}\left(m c_{G, t}^{n}\right)^{(1-\mu) \delta}\left(m c_{V, t}^{n}\right)^{\mu \delta}\left(m c_{M, t}^{n}\right)^{1-\delta}} .
\end{aligned}
$$




$$
w_{t}^{n}=\frac{W_{t}^{n}}{P_{t}^{n}}=A_{t}\left(m c_{G, t}^{n}\right)^{(1-\mu) \delta}\left(m c_{V, t}^{n}\right)^{\mu \delta}\left(m c_{M, t}^{n}\right)^{1-\delta} .
$$

Log-linearizing this we get,

$$
\widehat{w}_{t}^{n}=\widehat{A}_{t}+\Phi(1-\mu) \delta\left(\widehat{Y}_{O G, t}^{n}-\widehat{Y}_{P G, t}\right)
$$

From the labor supply equation,

$$
\widehat{w}_{t}^{n}=\psi \widehat{N}_{t}^{n}-(1-\sigma) \widehat{\Gamma}_{t}+\sigma \widehat{C}_{t}^{n}
$$

Substituting the value of $\widehat{N}_{t}^{n}=\Theta_{1}\left[\widehat{C}_{t}^{n}-\widehat{A}_{t}+(1-\mu)(\gamma-1) \delta\left(\widehat{Y}_{O G, t}^{n}-\widehat{A}_{G, t}\right)\right]+\Theta_{2}\left(\widehat{Y}_{P G, t}-\widehat{A}_{G, t}\right)$ above we get,

$$
\widehat{w}_{t}^{n}=\psi\left[\Theta_{1}\left[\widehat{C}_{t}^{n}-\widehat{A}_{t}+(1-\mu)(\gamma-1) \delta\left(\widehat{Y}_{O G, t}^{n}-\widehat{A}_{G, t}\right)\right]+\Theta_{2}\left(\widehat{Y}_{P G, t}-\widehat{A}_{G, t}\right)\right]-(1-\sigma) \widehat{\Gamma}_{t}+\sigma \widehat{C}_{t}^{n}
$$

Replacing $\widehat{w}_{t}^{n}$ with $\widehat{A}_{t}+\Phi(1-\mu) \delta\left(\widehat{Y}_{O G, t}^{n}-\widehat{Y}_{P G, t}\right)$ yields

$$
\begin{aligned}
\widehat{A}_{t}+\Phi(1-\mu) \delta\left(\widehat{Y}_{O G, t}^{n}-\widehat{Y}_{P G, t}\right)= & \psi \Theta_{1}\left[\widehat{C}_{t}^{n}-\widehat{A}_{t}+(1-\mu)(\gamma-1) \delta\left(\widehat{Y}_{O G, t}^{n}-\widehat{A}_{G, t}\right)\right] \\
& +\psi \Theta_{2}\left(\widehat{Y}_{P G, t}-\widehat{A}_{G, t}\right)-(1-\sigma) \widehat{\Gamma}_{t}+\sigma \widehat{C}_{t}^{n}
\end{aligned}
$$

Rearranging this to get $\widehat{C}_{t}^{n}$, we get equation (56)

$$
\begin{aligned}
\widehat{C}_{t}^{n}= & \frac{\left(\psi \Theta_{1}+1\right)}{\left(\psi \Theta_{1}+\sigma\right)} \widehat{A}_{t}-\frac{\left(\Phi(1-\mu) \delta+\psi \Theta_{2}\right)}{\left(\psi \Theta_{1}+\sigma\right)} \widehat{Y}_{P G, t}+\frac{(1-\sigma)}{\left(\psi \Theta_{1}+\sigma\right)} \widehat{\Gamma}_{t}+\delta \widehat{T}_{A M, t}^{n} \\
& +\frac{\left(\Phi(1-\mu) \delta-\psi \Theta_{1}(\gamma-1)(1-\mu) \delta\right)}{\left(\psi \Theta_{1}+\sigma\right)} \widehat{Y}_{O G, t}^{n}+\frac{\left(\psi \Theta_{1}(\gamma-1)(1-\mu) \delta+\psi \Theta_{2}\right)}{\left(\psi \Theta_{1}+\sigma\right)} \widehat{A}_{G, t} .
\end{aligned}
$$

\section{- Derivation of the sticky price equilibrium: equation (59)}

Using (41c) and (40) we get,

$$
\widehat{m c}_{M, t}=\psi \widehat{N}_{t}+\sigma \widehat{C}_{t}-(1-\sigma) \widehat{\Gamma}_{t}-\widehat{A}_{M, t}+\delta \widehat{T}_{A M, t}
$$

Putting the value of $\widehat{N}_{t}$ from (45), we get

$$
\begin{aligned}
\widehat{m c}_{M, t}= & \left(\psi \Theta_{1}+\sigma\right) \widehat{C}_{t}-\psi \Theta_{1}\left[\widehat{A}_{t}-(1-\mu)(\gamma-1) \delta\left(\widehat{Y}_{O G, t}-\widehat{A}_{G, t}\right)\right] \\
& +\psi \Theta_{2}\left(\widehat{Y}_{P G, t}-\widehat{A}_{G, t}\right)-(1-\sigma) \widehat{\Gamma}_{t}-\widehat{A}_{M, t}+\delta \widehat{T}_{A M, t}
\end{aligned}
$$


At the natural level, $\widehat{m c}_{M, t}^{n}=0$, which can also be written as,

$$
\begin{aligned}
0= & \left(\psi \Theta_{1}+\sigma\right) \widehat{C}_{t}^{n}-\psi \Theta_{1}\left[\widehat{A}_{t}-(1-\mu)(\gamma-1) \delta\left(\widehat{Y}_{O G, t}^{n}-\widehat{A}_{G, t}\right)\right] \\
& +\psi \Theta_{2}\left(\widehat{Y}_{P G, t}-\widehat{A}_{G, t}\right)-(1-\sigma) \widehat{\Gamma}_{t}-\widehat{A}_{M, t}+\delta \widehat{T}_{A M, t}^{n} \\
\widetilde{m c}_{M, t}= & \widehat{m c}_{M, t}-\widehat{m c}_{M, t}^{n}=\left(\psi \Theta_{1}+\sigma\right)\left(\widehat{C}_{t}-\widehat{C}_{t}^{n}\right)+\delta\left(\widehat{T}_{A M, t}-\widehat{T}_{A M, t}^{n}\right) \\
\widehat{m c}_{M, t}= & \left(\psi \Theta_{1}+\sigma\right) \widetilde{C}_{t}+\delta \widetilde{T}_{A M, t}
\end{aligned}
$$

Using demand functions, $\widetilde{C}_{t}=\widetilde{Y}_{M, t}-\delta \widetilde{T}_{A M, t}$, the above equation can be written as,

$$
\widehat{m c}_{M, t}=\left(\psi \Theta_{1}+\sigma\right) \widetilde{Y}_{M, t}-\delta\left(\psi \Theta_{1}+\sigma-1\right) \widetilde{T}_{A M, t} .
$$

